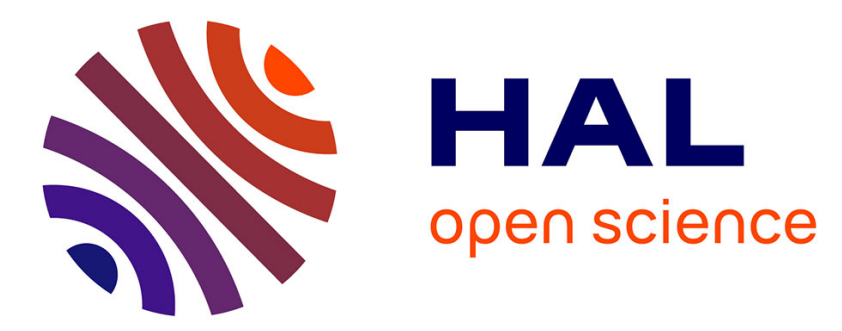

\title{
Main outcomes from the IVR code benchmark performed in the European IVMR project
}

\author{
L. Carénini, F. Fichot, N. Bakouta, A. Filippov, R. Le Tellier, L. Viot, I. \\ Melnikov, P. Pandazis
}

\section{- To cite this version:}

L. Carénini, F. Fichot, N. Bakouta, A. Filippov, R. Le Tellier, et al.. Main outcomes from the IVR code benchmark performed in the European IVMR project. Annals of Nuclear Energy, 2020, 146, pp.107612. 10.1016/j.anucene.2020.107612 . hal-03490651

\section{HAL Id: hal-03490651 https://hal.science/hal-03490651}

Submitted on 11 Jan 2022

HAL is a multi-disciplinary open access archive for the deposit and dissemination of scientific research documents, whether they are published or not. The documents may come from teaching and research institutions in France or abroad, or from public or private research centers.
L'archive ouverte pluridisciplinaire HAL, est destinée au dépôt et à la diffusion de documents scientifiques de niveau recherche, publiés ou non, émanant des établissements d'enseignement et de recherche français ou étrangers, des laboratoires publics ou privés.

\section{(ㅇ)(1) $\$$}

Distributed under a Creative Commons Attribution - NonCommercial - NoDerivatives| 4.0 


\title{
Main outcomes from the IVR code benchmark performed in the IVMR project
}

\author{
L. Carénini ${ }^{1}$, F. Fichot ${ }^{1}$, N. Bakouta ${ }^{2}$, A. Filippov ${ }^{3}$, R. Le Tellier ${ }^{4}$, L. Viot ${ }^{4}$, I. Melnikov $^{5}$, P. \\ Pandazis $^{6}$
}

\author{
${ }^{1}$ : IRSN, BP3 - 13115 St Paul lez Durance - FRANCE \\ ${ }^{2}$ : EDF, EDF Lab, Paris-Saclay, 7 boulevard Gaspard Monge, 91120 Palaiseau, FRANCE \\ ${ }^{3}$ : IBRAE, 52 B. Tulskaya St. Moscow, RUSSIA \\ ${ }^{4}:$ CEA, DEN, DTN/SMTA/LMAG, Cadarache - 13108 Saint Paul-lez-Durance - FRANCE \\ ${ }^{5}$ : NRC-KI, 1, Akademika Kurchatova pl., Moscow, 123182, RUSSIA \\ ${ }^{6}$ : GRS, Boltzmannstraße 14, 85748, Garching, GERMANY
}

laure.carenini@irsn.fr,florian.fichot@irsn.fr,nikolai.bakouta@edf.fr,phil@ibrae.ac.ru,romain.le-tellier@cea.fr, louis.viot@cea.fr, Melnikov_IA@nrcki.ru,Peter.Pandazis@grs.de

\begin{abstract}
In-Vessel Retention (IVR) of corium is one of the possible strategies for Severe Accident (SA) mitigation. Its main advantage lies in the fact that, by maintaining the corium within the vessel, the integrity of the last containment barrier against corium aggression is preserved. One of the issues for the demonstration of the success of this strategy is the evaluation of the behaviour of the corium relocated in the lower head and how it stabilizes and affects the integrity of the vessel wall. The first modelling was developed in the nineties and assessed the heat transfers in a stratified corium pool with a top metal layer made of steel and Zirconium only. About 10 years later, the results of the MASCA program highlighted the possibility of having more complex stratified configurations, including a dense metal layer. Addressing thermochemical effects in the stratification makes the modelling of the corium pool in the lower head more difficult and, in addition, knowledge of the associated kinetics is still limited. As a consequence, available SA codes, either integral or dedicated to the lower head, can differ significantly in their models, which leads to discrepancies in the results when evaluating the IVR strategy.

In order to identify the main modelling issues and to assess the capabilities of the codes, a benchmark exercise for code validation was made in the scope of the European H2020 project IVMR (In-Vessel Melt Retention). It is based on the definition of different IVR configurations at reactor scale with an increase in the complexity of the phenomena involved: starting from a steady-state stratified pool with metal on top, up to consideration of corium phase separation at thermochemical equilibrium and progressive ablation of metallic structures and vessel wall. As a last step, the more challenging transient configuration, with formation of a metal layer heavier than the oxide followed later on by stratification inversion, was also studied.

Six organisations took part in this benchmark (CEA, EDF, GRS, IBRAE, IRSN, NRC-KI) and 6 different codes were used (ASTEC, ATHLET-CD, MAAP_EDF, PROCOR, HEFEST_URAN and HEFEST - stand-alone version of the corresponding module of the SOCRAT code). The main results and outcomes obtained are presented and discussed in this paper. Sensitivity studies have also been performed and allow obtaining a more consolidated range of results.

Thanks to this benchmark exercise and to the approach followed with a progressive increase of complexity, the capabilities of codes to evaluate the heat flux profile applied to the vessel wall in steady-state are demonstrated. Then, for transient configurations, it is shown that different modelling approaches give rather consistent results since dispersion remains limited between code predictions, even in the most challenging configuration with stratification inversion: $\pm 40 \%$ for the minimum vessel thickness $(2.5 \mathrm{~cm} \pm 1 \mathrm{~cm})$. In addition, all codes predict that transient effects lead to more vessel ablation than in the final steady-state. Hence, the importance of the consideration of the progressive molten steel incorporation in the pool and of the consideration of thermochemical equilibrium to calculate the oxide and metal phases composition was highlighted in the benchmark.

Regarding the dispersion of the results obtained, analysis shows that uncertainties on metal layer properties have a significant impact. In addition, differences in modelling assumptions were identified and discussed. The main issues are related to the following physical phenomena: (i) The interaction of the oxide crust with the molten steel; (ii) The kinetics of stratification inversion; (iii) The heat transfer in thin metal layer.
\end{abstract}


Keywords: IVR strategy, SA codes benchmark, stratified corium pool evolution

\section{Introduction}

During a Severe Accident (SA) in Light Water Reactor (LWR), the lack of fuel cooling in the reactor vessel leads to core heat up and then melting of materials. The melt flows down to the lower plenum of the vessel. Consequently, the main part of the power generated by the fuel is not produced in the core zone anymore but at the bottom of the reactor pressure vessel (RPV). In such situation, a strategy of external cooling of the vessel wall (ERVC) to maintain the integrity of the vessel and to stabilize the corium inside the RPV may be used. This would reduce significantly the threats to the last barrier (the containment) and therefore reduce the risk of large release of low-volatile radioactive products to the environment. This In-Vessel Retention (IVR) strategy was introduced about 20 years ago (Henry and Fauske, 1993; Tuomisto and Theofanous, 1994). It was first applied to two designs of reactors: the AP600 (Theofanous et al., 1997), later replaced by the AP1000 design (Esmaili et al., 1997), and the VVER-440 (Kymälainen et al., 1997). Today, new reactor designs have been developed including this IVR strategy and first units become progressively operational: the Korean APR-1400 design (Knudson et al., 2004; Rempe et al., 2004; Whang et al., 2017) and the Chinese HPR-1000 design (Xing, 2017). At the same time, the possibility to apply IVR strategy as back-fitting measure to existing GEN II reactors is currently under consideration. In particular, the VVER1000 design attracts a lot of interest (Zdarek et al. 2013; Gencheva et al. 2016; Duspiva 2017).

Since the first evaluations performed in the nineties and the associated model developments, progresses in the understanding of the thermochemistry of the corium in the lower head when mixed with molten steel were made, mainly thanks to the results of the OECD MASCA 1 and 2 programs (Tsurikov, 2007). Indeed, it was found that the chemical interactions in the melt pool have a direct impact on its stratification and need to be considered in the evaluations of IVR strategy (Tuomisto and Sehgal, 2007). It appears then necessary to be able to describe the transient coupled thermal-hydraulics and chemical interactions that occurs in the melt pool to estimate the thermal load on the vessel wall. That makes the situation more difficult for code modelling compared to the previous standard configuration with the oxide pool being always below a top metal layer composed only of steel and Zirconium. In addition, the validation of such complex models requires further experimental efforts with prototypic materials.

As a consequence, available SA codes, either integral or dedicated to the lower head, can differ significantly in their models, which leads necessarily to discrepancies in the results when evaluating the IVR strategy. This issue was highlighted in the scope of the European H2020 project IVMR (In-Vessel Melt Retention), which aims at revisiting the SA strategy of IVR, in particular for reactor of "high-power", i.e. 1000 MWe or more (Fichot et al. 2018). In order to identify the main modelling issues and to assess the capabilities of the codes, a benchmark exercise was made with the codes' developers involved in the project: CEA with PROCOR code, EDF with a proprietary version of MAAP code (derivative of EPRI's MAAP5 code, referred to as MAAP_EDF in this paper), GRS with AIDA module of the ATHLET-CD code, IBRAE with HEFEST_URAN code, IRSN with ASTEC code and NRC-KI with HEFEST - stand-alone version of corresponding module of the SOCRAT code.

The description of this benchmark as well as the main results and outcomes are presented in this paper.

\section{Objectives and scope of the benchmark exercise}

This benchmark exercise involves several calculations cases defined with a progressive increase of complexity. From a standard configuration of corium layering in steady state with the metal layer on the top, it is proposed to investigate a transient situation considering a progressive increase of the mass of molten steel incorporated in the corium pool. The objective is to follow the variation of the heat fluxes applied to the vessel wall with time and compare the vessel wall ablation once reaching a steady state. Then, the effects of thermochemistry in the corium pool are investigated based on the same transient configuration.

To define the first step, the benchmark case used in the scope of AP600 and AP1000 designs development (Rempe et al., 1997; Esmaili and Khatib-Rahbar, 2004) was considered. Thus, the vessel geometry and the initial characteristics of the corium pool are specified (composition, residual power) and two cases are proposed depending on the assumption considered for the boundary condition on the top surface of the pool: adiabatic (case $\left.n^{\circ} 1\right)$ or radiative heat transfer towards surrounding structures considered at $950 \mathrm{~K}$ (case $\mathrm{n}^{\circ} 2$ ). Specifications of the calculations are summarized in Figure 1. For such simple configurations, thermochemistry in the corium pool is not considered and an analytical evaluation of average heat fluxes at the boundaries of each layer and of the layer 
temperatures is possible (cf. Appendix) and is then used for comparison with codes results. The vessel wall is considered only as a temperature boundary condition equal to the liquidus temperature of the stainless steel.

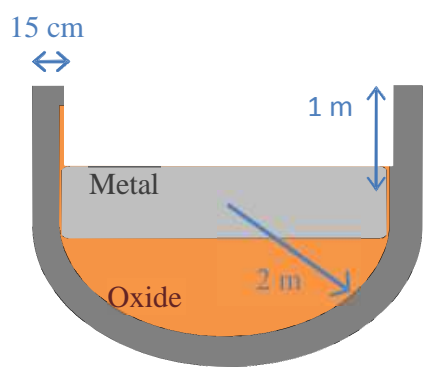

\begin{tabular}{|l|c|}
\hline Parameter & Value \\
\hline Oxide pool & $1.5 \mathrm{~m}$ \\
\hline Height of the oxide pool & $\begin{array}{c}0.8 \mathrm{UO}_{2}-0.2 \mathrm{ZrO}_{2} \\
\text { (mass fraction) }\end{array}$ \\
\hline Composition & $14 \mathrm{MW}$ \\
\hline Residual power & $0.9 \mathrm{~m}$ \\
\hline Metallic pool & $\begin{array}{c}\text { (m) stainless steel }-0.1 \mathrm{Zr} \\
\text { (mass fraction) }\end{array}$ \\
\hline Height of the metallic pool & Composition \\
\hline
\end{tabular}

Figure 1 Geometry of the lower head and corium configuration considered for the benchmark cases $n^{\circ} 1$ and 2

As a second step, in order to study transient effects, an additional case is proposed, in which the overall corium composition and decay heat at relocation in the lower head are imposed (as in previous cases), but the mass of molten steel incorporated increases progressively according to a prescribed kinetics to simulate the progressive melting of the metallic structures in the reactor vessel (cf. Table 1). Besides, the molten steel addition due to the vessel wall melting is also simulated, up to the steady state. In this case, the efficiency of the external vessel cooling is assumed and simulated using an imposed boundary condition (heat flux coefficient and water temperature). Firstly, the thermo-chemical equilibrium in the U-O-Zr-Fe quaternary system is not assumed (case $n^{\circ} 3$ ) in order to be consistent with steady state configurations described before.

In a third step, it is proposed to consider the effects of thermochemistry in the codes (when available) to identify the impact on the corium stratification (case $n^{\circ} 4$ ). It should be noted that, in this last case, the mass of non-oxidized Zirconium is not assumed to be mixed with the molten steel initially but with the oxide pool and the metal phase separation is expected to be evaluated by the code (cf. Table 1).

In addition, sensitivity calculations were performed based on the last transient configuration introduced above, which is the most complete and involved all the relevant phenomena. The main parameters identified as leading to the main differences in the steady-state configurations studied in the first step of the benchmark exercise were considered, in the range between lower and upper values implemented by default in the different codes used.

Finally, a fifth benchmark case was defined in order to simulate an inverse stratification with the metal layer being below the oxide and with stratification inversion of the pool during the transient. For that, the composition of the initial pool is modified in order to reduce the Zirconium oxidation degree, as well as the initial mass of steel (cf. Table 1). Even if, it is expected for such scenario to have a higher residual power in the oxide pool (low corium oxidation degrees usually correspond to faster scenarios, i.e. higher residual power), the value of $14 \mathrm{MW}$ considered in the previous calculations is kept for the sake of comparison.

Figure 2 summarizes the different initial corium pool configurations and associated boundary conditions considered in the 5 cases defined for the benchmark.

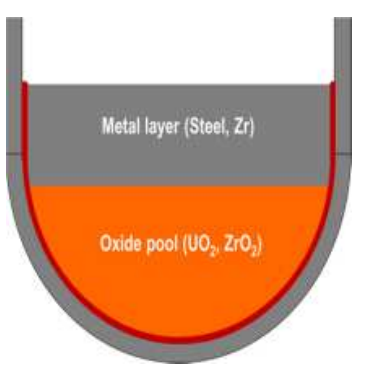

Cases $n^{\circ} 1$ and 2

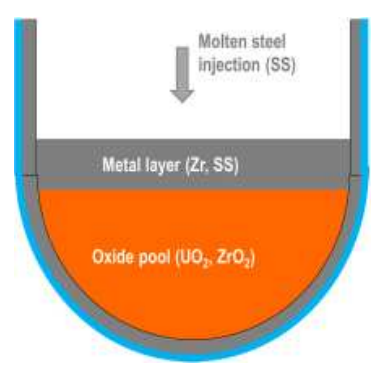

Case $n^{\circ} 3$

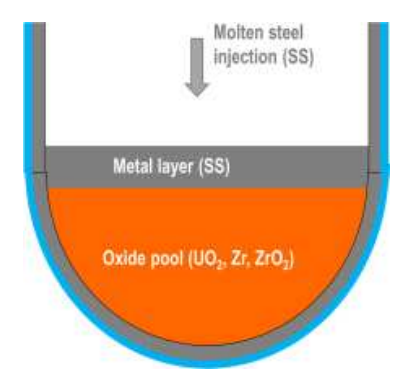

Case $n^{\circ} 4$

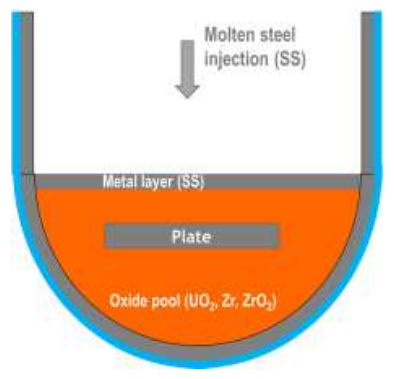

Case $n^{\circ} 5$

Figure 2 Lower plenum configurations specified in the benchmark cases - red: boundary condition imposed to the melting temperature of steel; blue: boundary condition of ERVC

Table 1 Corium characteristics considered for the benchmark cases $n{ }^{\circ} 3,4$ and 5 


\begin{tabular}{|c|c|c|c|c|c|}
\hline Parameter & Case $n^{\circ} 3$ & \multicolumn{2}{|c|}{ Case $n^{\circ} 4$} & \multicolumn{2}{|c|}{ Case $n^{\circ} 5$} \\
\hline \multicolumn{6}{|l|}{ Oxide pool } \\
\hline Height of the oxide pool & $1.5 \mathrm{~m}$ & \multicolumn{2}{|c|}{-} & \multicolumn{2}{|c|}{-} \\
\hline Composition & $\begin{array}{l}0.8 \mathrm{UO}_{2}-0.2 \mathrm{ZrO}_{2} \\
\text { (mass fraction) }^{\mathrm{i}}\end{array}$ & $\begin{array}{l}\text { UO2 mass } \\
\text { ZrO2 mass } \\
\text { Zr mass }\end{array}$ & $\begin{array}{l}68 \mathrm{t} \\
17 \mathrm{t} \\
7.5 \mathrm{t}\end{array}$ & $\begin{array}{l}\text { UO2 mass } \\
\text { ZrO2 mass } \\
\text { Zr mass }\end{array}$ & $\begin{array}{c}68 t \\
8 t \\
14 t \\
\end{array}$ \\
\hline Zr oxidation degree (Cox ${ }^{\mathrm{ii}}$ ) & - & & & & \\
\hline Residual power & \multicolumn{5}{|c|}{$14 \mathrm{MW}$} \\
\hline \multicolumn{6}{|l|}{ Metallic pool } \\
\hline Initial mass of $\mathrm{Zr}$ & $7.5 t$ & \multicolumn{2}{|c|}{-} & \multicolumn{2}{|c|}{-} \\
\hline Initial mass of molten steel & \multicolumn{3}{|c|}{$30 t$} & \multicolumn{2}{|c|}{$10 \mathrm{t}$} \\
\hline $\begin{array}{l}\text { Initial mass of solid steel } \\
\text { (internal structures }{ }^{\text {iii }} \text { ) }\end{array}$ & \multicolumn{3}{|c|}{-} & \multicolumn{2}{|c|}{$20 t$ initially at $450 \mathrm{~K}$} \\
\hline $\begin{array}{l}\text { Top relocation of molten } \\
\text { steel from } 9000 \text { s to } 14000 \text { s }\end{array}$ & \multicolumn{5}{|c|}{$6 \mathrm{~kg} / \mathrm{s}$ at melting temperature } \\
\hline
\end{tabular}

i This corresponds about $68 \mathrm{t}$ of $\mathrm{UO}_{2}$ and $17 \mathrm{t}$ of $\mathrm{ZrO}_{2}$ (depending on densities used in the codes) and to the masses specified for case $n^{\circ} 4$.

ii $C o x$ being the mole number of oxidized $\mathrm{Zr}$ divided by the mole number of total $\mathrm{Zr}$.

iii Cylindrical plate with a diameter of $3.15 \mathrm{~m}$ and a thickness of $33.5 \mathrm{~cm}$ located in the oxide pool (downward surface located $1.2 \mathrm{~m}$ above the bottom of the lower head) or equivalently a top relocation of molten steel from 800 s to 4,800 s with $5 \mathrm{~kg} / \mathrm{s}$ can be considered.

\section{Main features of codes}

The main modelling choices made in the six codes involved in this benchmark exercises are summarized in Table 2. The differences in terms of meshing for the vessel wall, the corium pool and the oxide crust are mentioned. In addition, the availability of a model to deal with thermochemical aspects in the corium pool is mentioned. The detail of these models will be discussed further in part 4.3, dealing with results obtained for case $n^{\circ} 4$.

More information about code capabilities may be found in associated publications Carénini and Fichot (2016) for ASTEC, Pandazis and Weber (2018) for ATHLET-CD, Filippov et al. (2010) for HEFEST_SOCRAT, Filippov et al. (2014) for HEFEST_URAN, Bakouta et al. (2017) for MAAP_EDF, and Le Tellier et al. (2015) for PROCOR.

Table 2 Main features of lower head modelling in codes

\begin{tabular}{|l|c|c|c|c|c|c|}
\cline { 2 - 6 } \multicolumn{1}{c|}{} & ASTEC & ATHLET-CD & $\begin{array}{c}\text { HEFEST- } \\
\text { SOCRAT }^{1}\end{array}$ & $\begin{array}{c}\text { HEFEST- } \\
\text { URAN }^{1}\end{array}$ & MAAP_EDF & PROCOR \\
\hline Vessel wall & 2D meshing & 2D meshing & 2D meshing & 2D meshing & 2D meshing & $\begin{array}{c}\text { 1D axial } \\
\text { meshing }\end{array}$ \\
\hline Corium pool & $\begin{array}{c}\text { OD meshing } \\
\text { Up to 3 layers }\end{array}$ & $\begin{array}{c}\text { 0D meshing } \\
\text { 2 layers }\end{array}$ & $\begin{array}{c}\text { 2D meshing } \\
\text { 2 layers }\end{array}$ & $\begin{array}{c}\text { 2D meshing } \\
\text { 2 layers }\end{array}$ & $\begin{array}{c}\text { OD meshing } \\
\text { Up to 3 layers }\end{array}$ & $\begin{array}{c}\text { 0D meshing } \\
\text { Up to } 4{ }^{2} \text { layers }\end{array}$ \\
\hline
\end{tabular}

\footnotetext{
${ }^{1}$ The difference between the HEFEST code versions implemented in the HEFEST_URAN package and in the SOCRAT code is due to the presence of some additional models in HEFEST_URAN: enclosure radiation, in-vessel melt relocation from the core barrel, FAS-model (detailed consideration of side-wall heat flux), models of meltwater interaction, shrinkage and some other used for in-vessel and ex-vessel melt simulations. But the solver and kernel models of melt-structure interaction are practically the same in the both versions, and the listed additional models were not activated in the benchmark calculations performed with HEFEST_URAN. For this benchmark, the default heat transfer model of HEFEST module (based on effective thermal conductivity and described in the paper (Filippov et al., 2010)) was used both in HEFEST_URAN and in HEFEST_SOCRAT simulations and a model with controlled interlayer boundary heat transfer was chosen. The correlations for effective heat source replacing the upper boundary heat transfer in this model corresponded to analytical solution (cf. Appendix).

${ }^{2}$ When stratification inversion occurs, an additional metal layer below the oxidic crust and above the oxidic pool appears based on the assumption that the crust is stable (see $\$ 4.3$ ).
} 


\begin{tabular}{|l|c|c|c|c|c|c|}
\cline { 2 - 6 } \multicolumn{1}{c|}{} & ASTEC & ATHLET-CD & $\begin{array}{c}\text { HEFEST- } \\
\text { SOCRAT }^{1}\end{array}$ & $\begin{array}{c}\text { HEFEST- } \\
\text { URAN }^{1}\end{array}$ & MAAP_EDF & PROCOR \\
\hline Oxide crust & $\begin{array}{c}\text { Explicitly } \\
\text { modeled with the } \\
\text { vessel, not } \\
\text { considered } \\
\text { between oxide } \\
\text { and metal layers }\end{array}$ & $\begin{array}{c}\text { Explicitly } \\
\text { modeled } \\
\text { resistance }\end{array}$ & $\begin{array}{c}\text { Explicitly } \\
\text { modeled }\end{array}$ & $\begin{array}{c}\text { Explicitly } \\
\text { modeled } \\
\text { resistance and } \\
\text { physical } \\
\text { barrier for } \\
\text { chemical } \\
\text { interaction }\end{array}$ \\
\hline $\begin{array}{l}\text { Thermo-chemical } \\
\text { equilibrium in } \\
\text { U-O-Zr-Fe system }\end{array}$ & Yes & No & Yes & Yes & Yes & Yes \\
\hline
\end{tabular}

"For the oxide crust, "explicitly modeled" means that the mass variation of the crust is calculated from thermal balance. Compared to "thermal resistance", it means that the energy needed for the crust melting or growth is considered.

\section{Results and outcomes}

\subsection{Steady-state standard configurations}

For steady-state configurations, two different boundary conditions have been simulated for the top of the metal layer, modelling or not the radiative heat transfer (respectively referred to as case $n^{\circ} 2$ and $n^{\circ} 1$ ). The results obtained for the average heat fluxes at the boundaries of the corium pool and between layers are summarized in Figure 3 . A good agreement between the evaluations may be observed with dispersion below $10 \%$ in the adiabatic case and up to $17 \%$ for the heat flux from the metal layer to the vessel wall in the case $n^{\circ} 2$, directly associated to the variation in the radiative heat flux evaluated at the top of the metal layer (variation around 50\%).

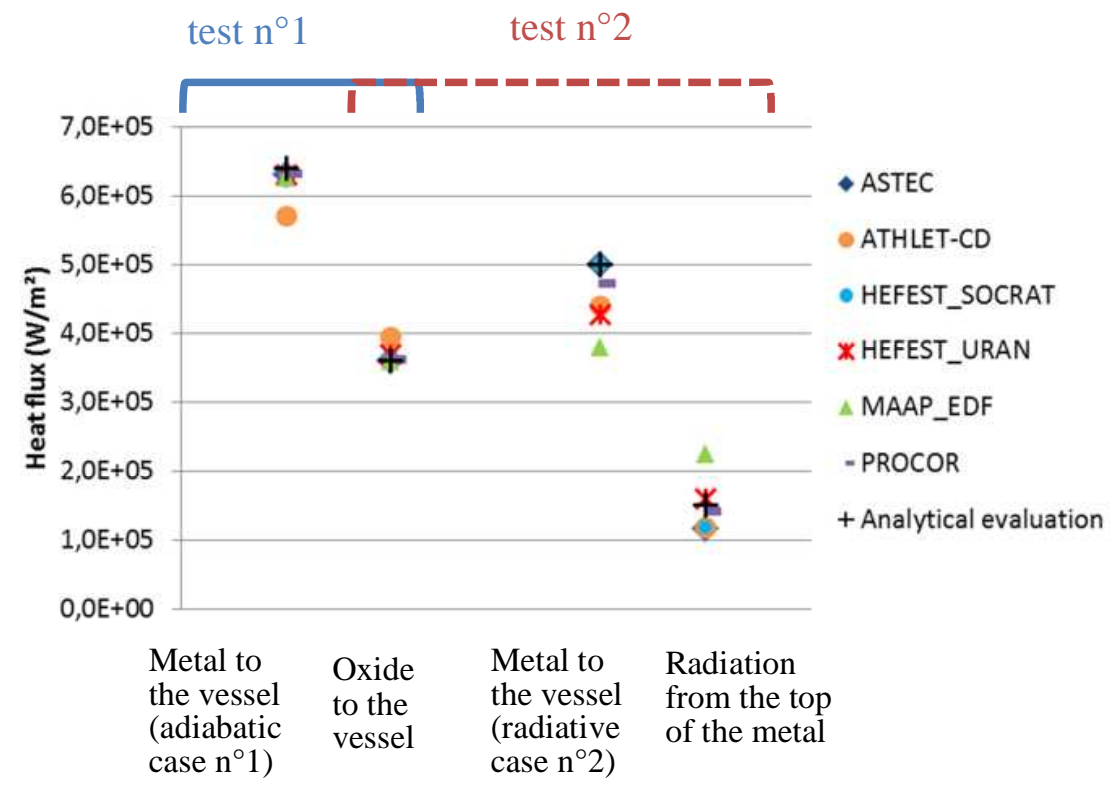

Figure 3 Average heat fluxes evaluated for the benchmark cases $n^{\circ} 1$ and 2

Even if such variations (below 20\%) for the heat flux applied to the vessel wall may be considered as acceptable regarding the IVR issue, these simple configurations were studied further in order to identify the main reason for the variation of the heat flux evaluated by the different codes.

The first difference is associated to the correlation chosen for the heat transfers in the oxide pool, which determines the power split between the lateral surface with the vessel and the top surface. It is evaluated to 0.44 in ATHLETCD code which uses Asfia-Dhir correlation (1996) in the presented simulation for the heat transfers towards the 
vessel $^{3}$ compared to $0.52 \pm 0.01$ in other codes based on COPO/BALI correlations (Bonnet and Seiler, 1999). This difference mainly explains the discrepancy in the heat flux profiles evaluation with ATHLET-CD and the other codes (cf. Figure 4, case $n^{\circ} 1$ ), especially the underestimation of the heat flux at the top layer location since the power transmitted from the oxide pool to the metal layer is reduced of about $8 \%$. It should be highlighted that AsfiaDhir correlation is valid for Rayleigh numbers $2.10^{10}<\mathrm{Ra}_{\mathrm{i}}<10^{14}$, whereas COPO/BALI correlation is applicable to higher values $10^{13}<\mathrm{Ra}_{\mathrm{i}}<10^{17}$ and thus more adapted to the current simulations $\left(\mathrm{Ra}_{\mathrm{i}} \sim 3.10^{15}\right.$, cf. Appendix).
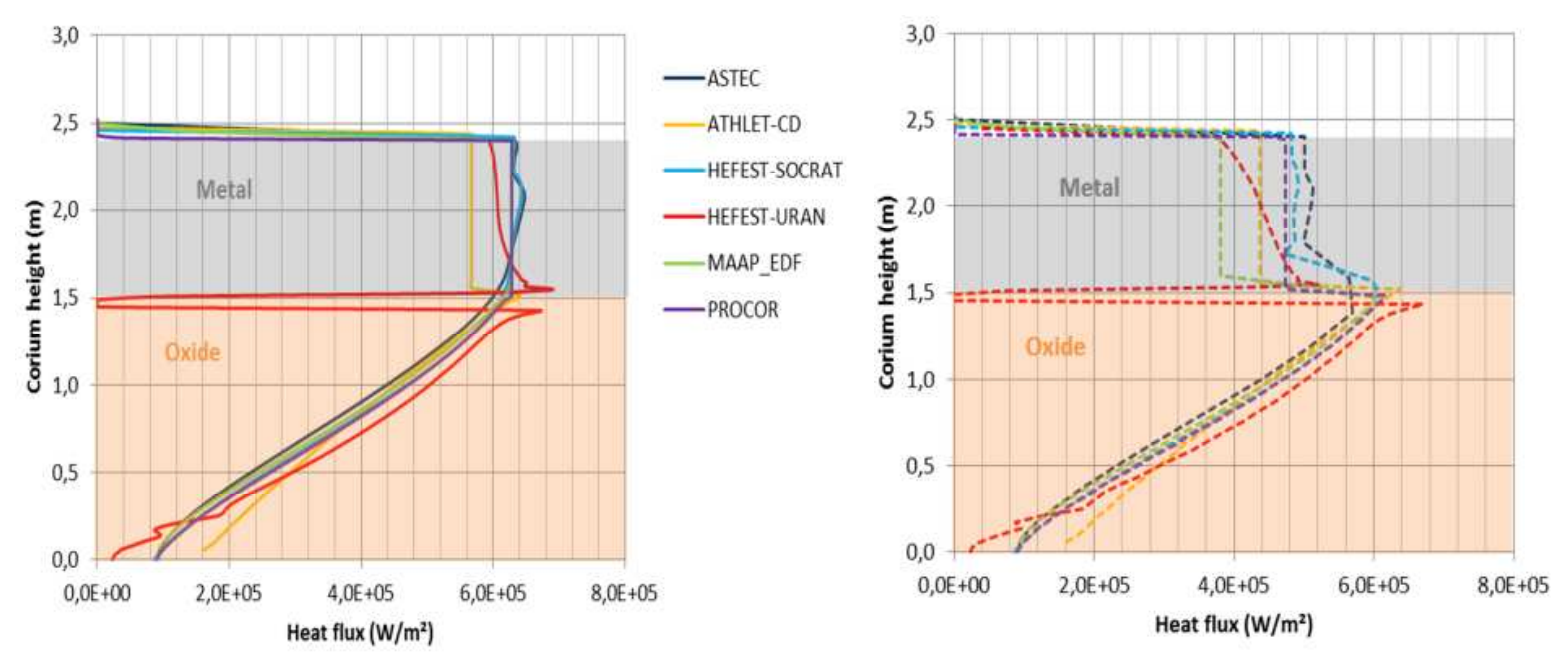

Figure 4 Heat flux profiles evaluated at steady state for the benchmark case $n^{\circ} 1$ (left) and $\operatorname{case} n^{\circ} 2$ (right)

Regarding the heat flux profile along the vessel wall, which determines the maximum value of heat flux, it is observed that all codes have similar correlations for the hemispheric part of the wall, with a comparable value evaluated for the maximum heat flux at the top of the oxide pool. In HEFEST-URAN simulation, at the location of the oxide crust, the heat flux to the vessel wall is drastically reduced due to the thin insulating layer introduced between the oxide and metal layers. Heat transfer from oxide to metallic layer is modelled here as an equivalent volumetric heat source in the metallic layer that is described in Filippov et al. (2014). Local peaks of heat flux at both sides of the phase boundary are not obtained in realistic case and are due to the benchmark case definition with a prescribed boundary temperature instead of the vessel wall. Indeed, depending on the code, this boundary condition may be difficult to impose.

In Figure 5, the temperatures obtained for the layers are presented. It appears that significant differences may happen due to differences in the material properties considered. It is recalled that it was recommended to use the default value of material properties available in each code. The range of variation is summarized in Table 3.

\footnotetext{
${ }^{3}$ For the heat transfers towards the top surface of the oxide pool, the correlation of Kelkar (Kelkar et al., 1993) is used in ATHLET-CD.
} 


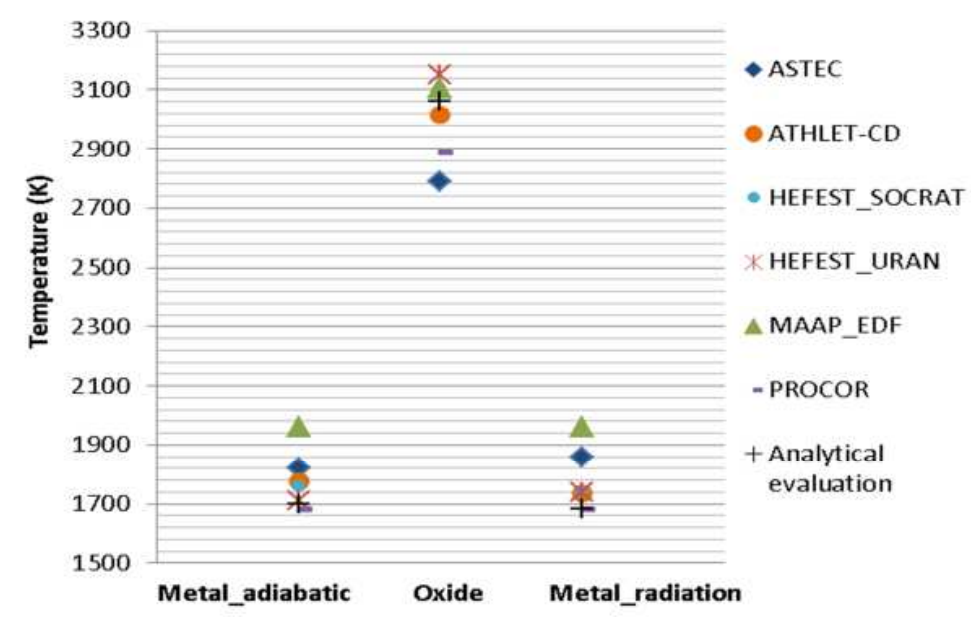

Figure 5 Layers temperatures evaluated at steady state for the benchmark cases $n^{\circ} 1$ and 2

Table 3 Range of variation of layers properties considering all the different codes ${ }^{4}$

\begin{tabular}{|c|c|c|c|}
\hline & Parameter & Value & Variation \\
\hline \multirow{6}{*}{$\begin{array}{l}\overline{8} \\
\stackrel{0}{a} \\
\frac{0}{2} \\
\\
0\end{array}$} & Density & $7711-8300 \mathrm{~kg} / \mathrm{m}^{3}$ & $\pm 4 \%$ \\
\hline & Thermal conductivity & $2.3-7.07 \mathrm{~W} / \mathrm{m} / \mathrm{K}$ & $\pm 51 \%$ \\
\hline & Dynamic viscosity & $4.57-5.27 \times 10^{-3} \mathrm{~m}^{2} / \mathrm{s}$ & $\pm 7 \%$ \\
\hline & Specific heat capacity & $520-604 \mathrm{~J} / \mathrm{kg} / \mathrm{K}$ & $\pm 7 \%$ \\
\hline & $\begin{array}{l}\text { Thermal expansion } \\
\text { coefficient }\end{array}$ & $2.61 \times 10^{-5}-1.05 \times 10^{-4} \mathrm{~K}^{-1}$ & $\pm 60 \%$ \\
\hline & Melting temperature & $2600-2950 \mathrm{~K}$ & $\pm 6 \%$ \\
\hline \multirow{7}{*}{ 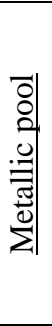 } & Density & $6763-7156 \mathrm{~kg} / \mathrm{m}^{3}$ & $\pm 3 \%$ \\
\hline & Thermal conductivity & $19.65-38.4 \mathrm{~W} / \mathrm{m} / \mathrm{K}$ & $\pm 32 \%$ \\
\hline & Dynamic viscosity & $4.07 \times 10^{-3}-2.24 \times 10^{-2}$ Pa.s & $\pm 69 \%$ \\
\hline & Specific heat capacity & $538-789.5 \mathrm{~J} / \mathrm{kg} / \mathrm{K}$ & $\pm 19 \%$ \\
\hline & $\begin{array}{l}\text { Thermal expansion } \\
\text { coefficient }\end{array}$ & $2.9 \times 10^{-5}-1.17 \times 10^{-4} \mathrm{~K}^{-1}$ & $\pm 60 \%$ \\
\hline & Melting temperature & $1600-1778 \mathrm{~K}$ & $\pm 5 \%$ \\
\hline & Emissivity & $0.2-0.4$ & $\pm 33 \%$ \\
\hline
\end{tabular}

Since the melting temperature of the oxide (resp. the metal) considered in the different codes varied in the range 2600K-2950K (resp. 1600K-1723K), it is better to compare the results in terms of layer superheat above its melting temperature as presented in Figure 6 (resp. Figure 7).

\footnotetext{
${ }^{4}$ Values estimated when steady state is reached, i.e. at the corresponding temperature.
} 


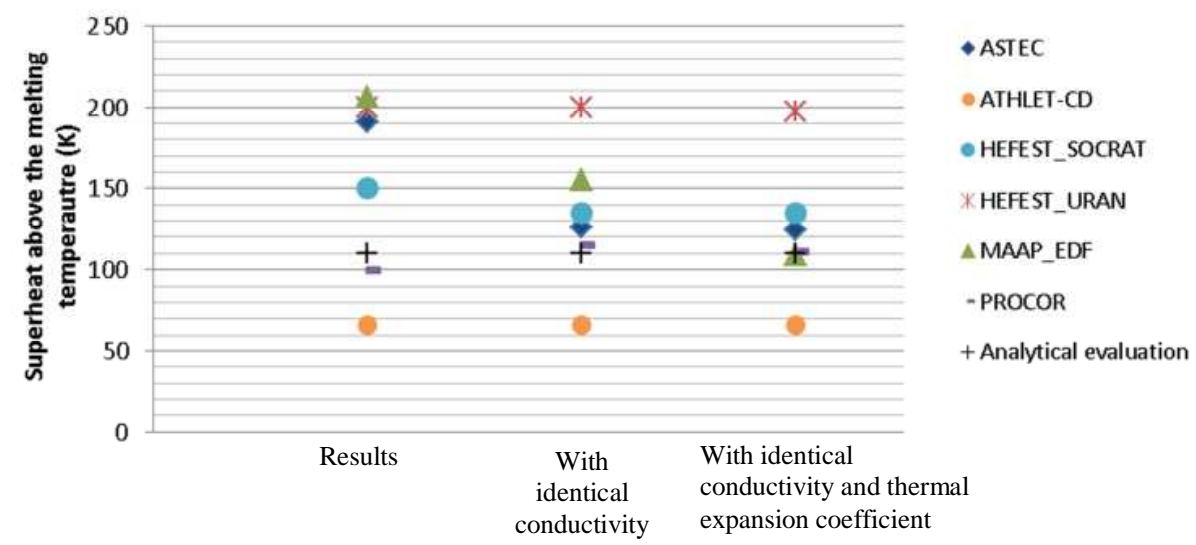

Figure 6 Oxide superheat and impact of dispersion in material properties (analytical evaluation being considered here as reference)

A significant spread of the results is observed for the oxide layer temperature. This can be related to the discrepancy in the value of the oxide conductivity and in the thermal expansion coefficient as illustrated in the graph with the reduction of the dispersion when variation due to the value of the conductivity and then conductivity plus thermal expansion coefficient are considered. Indeed, the conductivity of the oxide layer has a significant dispersion $( \pm 51 \%)$ and considering COPO/BALI correlation, the conductivity of the oxide impacts the temperature superheat at the power -0.5 (cf. appendix). The dispersion of the thermal expansion coefficient is also significant $( \pm 60 \%)$ even if its contribution is reduced (power -0.25). For ATHLET-CD results, it should be noted that the material properties were taken equal to the ones considered in the analytical calculation ${ }^{5}$. The discrepancies observed are not only due to the differences in correlations used for the heat transfers in the oxide pool mentioned before (in this case an overestimation of the oxide temperature would have been expected), but mainly to the fact that the oxide crust between the oxide pool and the metal layer is not simulated. With such assumption, the oxide behaviour is dependent on the characteristics of the metal layer, which is not the case in the evaluations performed with the other codes. In the analytical evaluation (cf. appendix), the assumption of a crust between the oxide and the metal layer is also made, since such a crust is expected in the reactor case due to the temperature difference between the oxide and the metal. For HEFEST-URAN results, the reason for having a higher oxide temperature compared to the other codes is in insulating properties of solid crust formed at the cold boundary. This is due to the specificity of benchmark configurations $\mathrm{n}^{\circ} 1$ and 2 with imposed boundary temperature which is difficult to implement in somecodes built to consider a vessel wall with a thermal resistance in contact with the oxide pool. .

Regarding the metal layer temperature dispersion, the influence of the material properties, in particular, the viscosity and the thermal expansion coefficient, may be highlighted (cf. Figure 7). For this evaluation, it is assumed that these properties influence the metal layer temperature for a given heat flux transmitted to the vessel wall according to Chawla-Chan correlation (1982) as done in analytical evaluation (cf. appendix). The dispersion in the heat conductivity appears more limited compared to the one of the oxide layer. It is worth noting that the dispersion of the Prandtl number of the metal layer among the different simulations is significant: $0.08-0.8$.

In addition to these effects, the correlation of heat transfers from the metal layer to the vessel wall may also play a role. All the codes use the Chawla and Chan correlation (1982) or equivalently the Churchill and Chu one, (1975) except ATHLET-CD in which the COPO/BALI correlations are used in the metal layer. In addition, the implementation of this correlation in ASTEC is done using the radius as characteristic length for the layer instead of its thickness as done in other codes and in the analytical evaluation presented in appendix. This choice was made to avoid non-physical results when the layer height tends to 0, leading to evaluate an infinite heat flux. This leads to multiply in this case the metal super-heat by a factor 1.25, as shown in Figure 7. Here again, the discrepancy in the evaluation by ATHLET-CD has to be associated to the fact that the thermal resistance from the oxide crust is neglected between the oxide and the metal, increasing the metal temperature.

\footnotetext{
${ }^{5}$ For properties defined in Table 4. For other properties, in particular dealing with the oxide crust formation, default values of ATHLET-CD codes are used.
} 


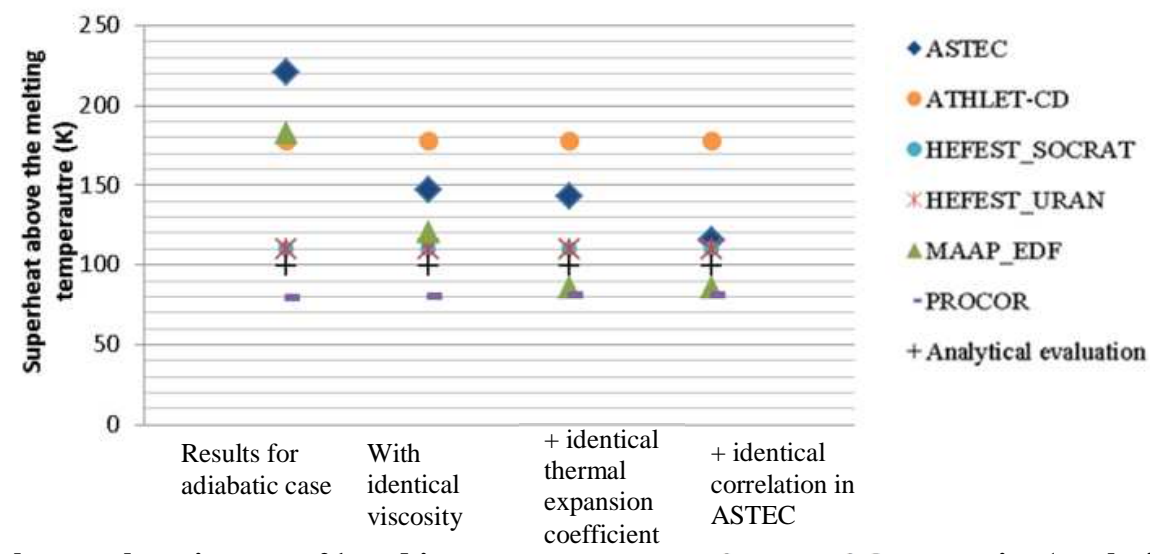

Figure 7 Metal super-heat in case $n^{\circ} 1$ and impact of dispersion in material properties (analytical case being considered as the reference here) and characteristics length

In case $n^{\circ} 2$, with top radiative condition, the dispersion of the metal layer temperature (cf. Figure 8 (a)) has also to be related with the dispersion in the emissivity considered for the radiative heat transfer (in the range 0.21-0.4 in those simulations). In this case, the relative influence of the material properties and of the correlations is more difficult to identify. Looking at the power split in the metal layer between radiation and convection towards the vessel wall (cf. Figure 8 (b)), a significantly higher value for the MAAP_EDF simulation is observed. This may be first related to the effect of the metal viscosity and thermal expansion coefficient, which impacts directly the temperature of the metal layer, as identified before (cf. Figure 7). Then, in this case, the melting temperature of the layer is higher $(1778 \mathrm{~K})$ compared to the analytical case $(1600 \mathrm{~K})$ and it also plays a role in the increase of the power dissipated by radiative heat transfer. In comparison, for ASTEC simulation, the reduced power fraction dissipated by radiation considering the high super-heat of the layer should be linked to the emissivity of the metal layer which is considered equal to 0.21 in this simulation against 0.38 in MAAP_EDF case and in the analytical case. Those appear to be the main reasons for the lower value of the evaluated heat flux applied to the vessel wall in the MAAP_EDF case $n^{\circ} 2$ simulation (cf. Figure 4).

(a)

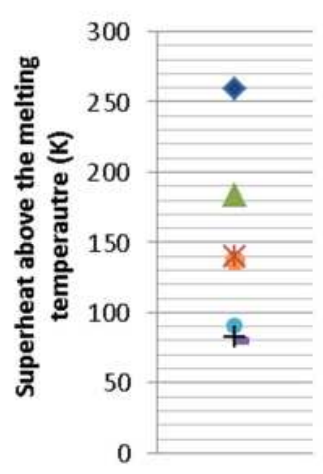

Figure 8 Metal superheat (a) and fraction of the power dissipated by the metal layer, which is lost by radiative heat transfer $(b)$ in case $n^{\circ} 2$

To conclude this first part of the benchmark exercise, it was shown that, despite the simplicity of the configurations studied, a lot of interesting outputs can be drawn. In such configurations, an analytical evaluation is possible and appears to be a good tool to interpret the results given by the codes. This allows identifying the parameters or material properties with the highest impact on the final heat flux applied to the vessel wall:

- In adiabatic case, only the correlations used in the oxide pool have an impact on the heat flux. This discrepancy may be limited when using the "best estimate" correlations, i.e. the correlations which have been validated for the highest Rayleigh numbers. 
- In the case with radiative heat loss, the temperatures evaluated for the layers have an impact on the heat flux applied to the vessel wall since the power dissipated by radiation is directly linked with the metal layer temperature. In this case, the impact of the uncertainties on the material properties was highlighted:

○ The metal layer has the largest impact, with, first, its viscosity, then its melting temperature and its emissivity. A large uncertainty on the value of the thermal expansion coefficient was also identified.

- The oxide layer impact comes from its conductivity and its thermal expansion coefficient but it remains of second order compared to the metal properties.

These conclusions on influence of material properties and in particular of the ones of the metal phase are in accordance with the outputs of the Phenomena Identification Ranking Table (PIRT) on IVR modelling (Fichot et al., 2019).

\subsection{Transient with standard configuration}

Transient configurations were also studied, considering a progressive incorporation of steel due to the melting of the internal structures in the vessel and evaluating the vessel wall ablation till reaching a stabilized situation. The initial corium composition at core relocation considered in this case is the same as the one defined for the first calculations, except for the steel mass which is reduced in order to simulate the progressive melting of the different metallic structures (cf. Table 1). For the sake of comparison between codes and to focus on the corium pool behaviour, the kinetics of molten steel addition in the corium pool are prescribed $\left(6 \mathrm{~kg} / \mathrm{s}\right.$ from $2 \mathrm{~h} 30(9,000 \mathrm{~s})$ to about $\left.4 \mathrm{~h}(14,000 \mathrm{~s})^{6}\right)$ instead of letting the codes simulate the progressive melting of the structures itself. This molten steel is supposed to be at its melting temperature. The radiative boundary condition defined in case $n^{\circ} 2$ is considered. It should be noted that in ATHLET-CD code, it was not possible to impose this arrival of molten steel during the stand alone lower plenum simulation. Thus, the results are considered only for the first phase (up to 9,000s).

In Figure 9, the heat flux profile at the outer surface of the vessel wall, at the time when the maximum value is reached during the transient is presented. For all codes, the maximum value is reached before the beginning of the molten steel addition at $9,000 \mathrm{~s}$. It is evaluated in front of the top metal layer whose thickness is reduced to about $50 \mathrm{~cm}$ (including molten steel from vessel ablation, against $90 \mathrm{~cm}$ in the previous steady states). Values are in the range $0.55-0.85 \mathrm{MW} / \mathrm{m}^{2}$.

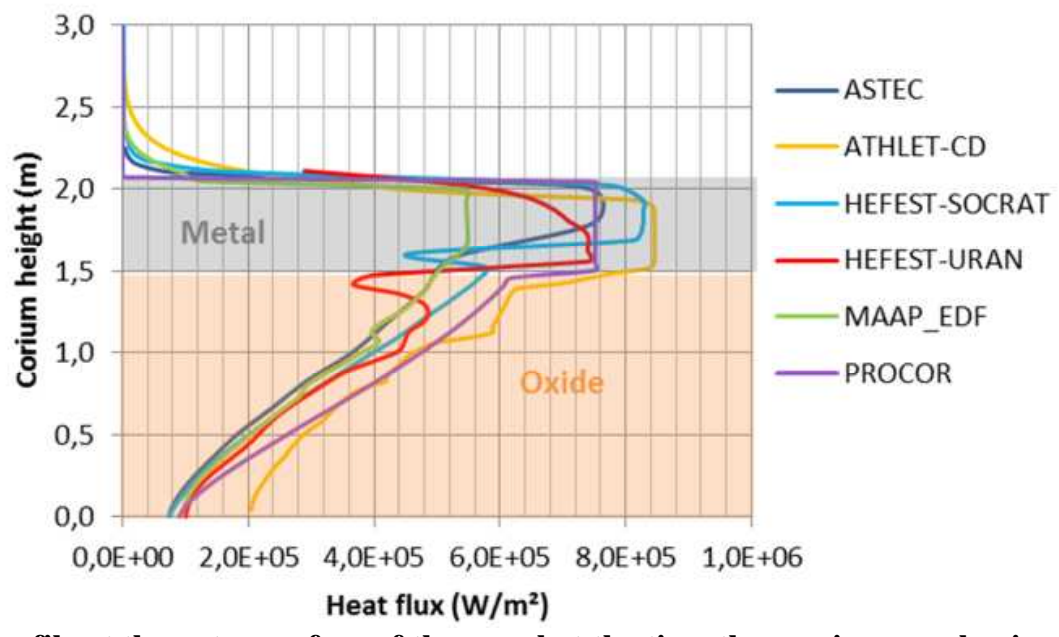

Figure 9 Heat flux profile at the outer surface of the vessel at the time the maximum value is reached (case $\mathbf{n}^{\circ}$ )

Based on the understanding of the differences between the codes presented in the previous part, it appears that the lowest value is associated to the strong radiative heat flux evaluated in this case in MAAP_EDF code, and mainly

\footnotetext{
${ }^{6}$ The rate of $6 \mathrm{~kg} / \mathrm{s}$ is evaluated considering a power of $1.8 \mathrm{MW}$ due to radiative heat transfer from the top surface of the corium pool and an enthalpy of fusion of steel equal to $300 \mathrm{~kJ} / \mathrm{kg}$. The order of magnitude of the time needed to heat these metallic structures up to the melting point (2h30) is evaluated considering a power of $1.8 \mathrm{MW}$ coming from the corium pool, an initial temperature of $600 \mathrm{~K}$ and an average heat capacity of $540 \mathrm{~J} / \mathrm{K} / \mathrm{kg}$ over the range $[600 \mathrm{~K}-1600 \mathrm{~K}]$.
} 
linked to the values of the metal layer properties (high emissivity and high melting temperature in particular). This is confirmed in Figure 10 a) where the power dispersion is presented for all simulations. In MAAP_EDF up to $25 \%$ is dissipated thanks to the radiative heat transfer at 9,000s.

During the transient, the two phases are clearly visible in all simulations: at the beginning, the residual power is only partly dissipated through the vessel and the rest is used to heat up the pool and the vessel wall and progressively melt it. This leads to the increase of the power fraction dissipated by external cooling. A quasi steady state is reached before the beginning of the molten steel injection at the top of the pool. This steel is at the liquidus temperature and needs to be heated up to reach again a stable configuration in which the residual power is entirely extracted by the external cooling and by the radiative heat transfer.
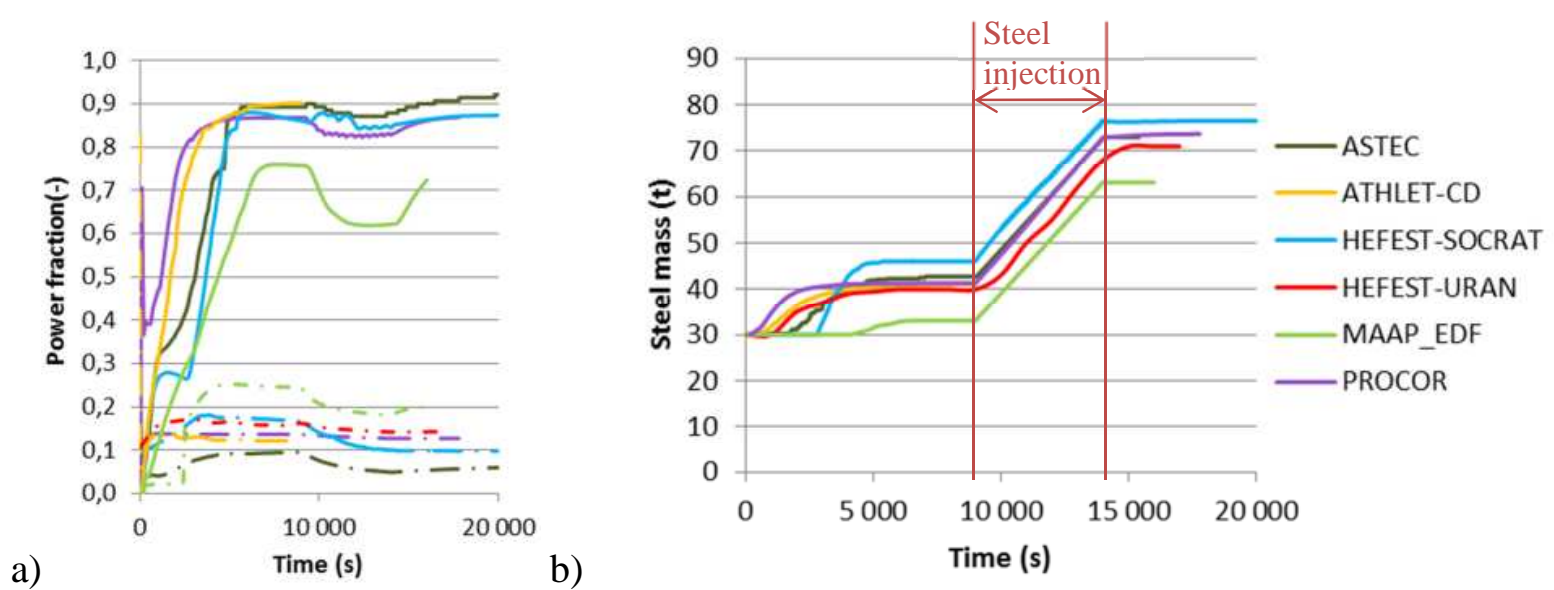

Figure 10 a) Fraction of residual power dissipated by the external cooling ${ }^{7}$ (full lines) and by the radiation at the top of the pool (dashed lines); b) Evolution of the mass of molten steel incorporated in the metallic layer $\left(\right.$ case $\mathbf{n}^{\circ}$ )

In Figure $10 \mathrm{~b}$ ), the evolution of the mass of steel added to the metal layer is presented. It appears that the melting of the vessel wall happens mainly at the beginning of the transient and leads to addition of about 10-15t of steel into the metal layer, except for the MAAP_EDF simulation in which the mass of molten steel added in the top layer from the vessel ablation is limited to 3t. This is of course directly linked with the evaluation of a smaller heat flux applied to the vessel wall in front of the metal layer due to larger dissipation by radiation. In addition, in ASTEC and MAAP_EDF simulations, the molten steel from the vessel wall in front of the oxide pool is kept in this layer and not considered in the evaluation presented in Figure $10 \mathrm{~b}$ ), since thermochemical models are disabled in this case. It represents an additional mass of $7 \mathrm{t}$ in ASTEC and 4.7t in MAAP.

The profiles of ablated vessel wall obtained at steady state are summarized in Figure $11 \mathrm{a}$ ). The minimum thickness is reached in front of the bottom of the metallic layer, where the maximum heat flux was reached during the transient. The value is in the range $3-7 \mathrm{~cm}$. The dispersion of $\pm 21 \%$ in the maximum heat flux evaluated at the outer surface of the vessel wall leads to a dispersion of $\pm 40 \%$ in the evaluation of the minimum vessel thickness. If the particular case of MAAP_EDF calculation is not considered, the variability of the minimum thickness is reduced to $\pm 25 \%$ corresponding to $\pm 1 \mathrm{~cm}$. It is worth noting that, in HEFEST-URAN simulation, the modelling of the oxide crust limits the heat flux and hence, the vessel ablation at its location.

Compared to the equivalent steady state case $n^{\circ} 2$, the maximum heat flux is multiplied by a factor 1.4-1.7. The steady-state profiles of heat flux at the outer surface of the vessel wall obtained are summarized in Figure $11 \mathrm{~b}$ ). Except for the PROCOR result, these profiles significantly differ from the ones calculated in the case $n^{\circ} 2$, showing the importance of simulating the transient scenario to catch the evolution of the vessel ablation which has a direct impact on the heat flux distribution at the end. Indeed, it is shown that at the location of the minimum vessel thickness (between elevations 1.5-2m), the heat flux remains higher, even if the thickness of the top metal layer has increased (up to $2.5 \mathrm{~m}$ ). This effect is not visible in the PROCOR simulation due to the simplified meshing of the vessel wall which is used (1D axial meshing).

The reason for higher ablation of the vessel wall in the oxide part in HEFEST-SOCRAT simulation may be associated to the conductivity considered for the vessel wall, since the heat fluxes obtained at this location are

\footnotetext{
${ }^{7}$ Data not available for HEFEST-URAN simulation
} 
comparable with other simulations and ablation in front of the metal layer is also more significant with respect to the level of maximum heat flux evaluated (cf. Figure 9).
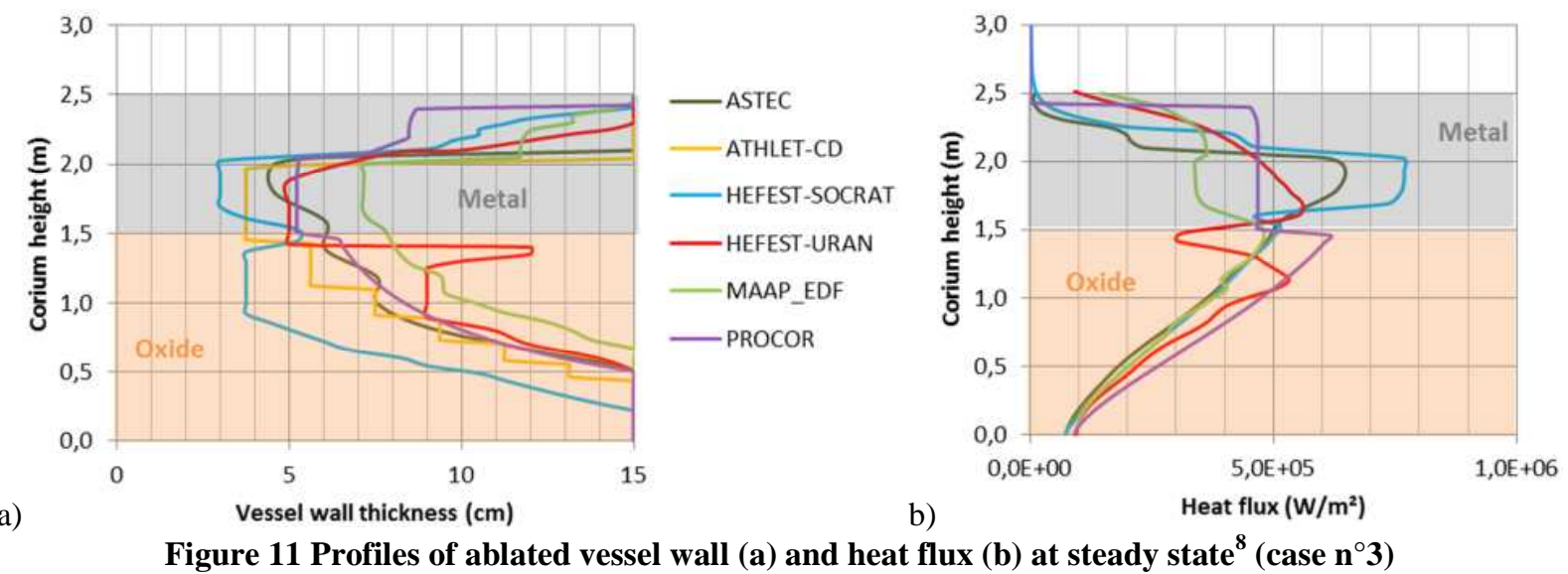

The analysis of this case $n^{\circ} 3$, allows a clear identification of the impact on the minimum vessel thickness of the kinetics of molten steel addition. Depending on the time necessary to heat up and melt the metallic structures and in particular for structures located above the molten pool, a transient maximum heat flux may be reached for a time sufficiently long to melt the vessel wall more than in the "virtual" steady state case. This ablated profile of the vessel has an impact on the heat flux profiles obtained in steady state: the reduction of the thermal resistance at the location of the minimum vessel thickness obtained in transient configuration, leads to an increase of the heat flux at the external vessel surface at this location at steady state.

\subsection{Influence of thermochemical phenomena}

\section{$\underline{\text { Standard configuration }}$}

In this test, the thermochemical phenomena occurring in the corium pool are taken into account when associated modelling is available in the codes (ATHLET-CD did not take part to this calculation). Indeed, in the cases before, the non-oxidized Zirconium was considered initially mixed with the molten steel. In reality, when the corium relocates from the core part it is composed of $\mathrm{UO}_{2}$ and partially oxidized Zirconium $\left(\mathrm{ZrO}_{2}, \mathrm{Zr}\right)$. Then, when mixed with molten steel, the metal and the oxide phases become non-miscible and the metal phase becomes enriched not only in Zirconium but also in metallic Uranium. Thus, compared to the previous simple assumption, the composition of the metal phase at thermochemical equilibrium differs, with less $\mathrm{Zr}$ and more $\mathrm{U}$. In addition, due to this interaction, fission products which have affinity with the metal phase migrate in this layer leading to partition of the residual power between the metal and oxide layers.

Results of heat flux profiles when the maximum is reached at the outer surface of the vessel are presented in Figure 12. A strong variation of the maximum heat flux is observed in the PROCOR simulation, where the maximum heat flux is reached at the top of the metal layer before injection of molten steel. This high heat flux (up to $5 \mathrm{MW} / \mathrm{m}^{2}$ ) is due to a strong focusing effect occurring in a thin top layer of steel, once the molten steel has interacted with the oxide pool and been transferred below the oxide crust, as shown in Figure 14, with the progressive reduction of top metal layer thickness before molten steel injection and after the stop of injection. In other codes, such assumption regarding the metal relocation below the oxide crust is not made and the oxide crust is supposed to remain at the interface between the oxide and the metal layer, even during chemical interaction and transfer of Zirconium and Uranium in the metal layer. Despite the decrease of the oxide pool mass/height during this interaction, no oxide crust is considered in front of the metal layer (along the vessel wall), assuming that it will lose its integrity. In PROCOR code, this lateral oxide crust in front of the metal layer after its interaction with this oxide leads to significantly decrease the heat flux at this location (below $0.2 \mathrm{MW} / \mathrm{m}^{2}$ ).

\footnotetext{
${ }^{8}$ Note that, for ATHLET-CD simulation, the ablated profile is obtained at the end of the first phase without considering the injection of molten steel. Heat flux profile at steady state is not compared.
} 
Not considering the case of PROCOR code, the maximum heat fluxes obtained $\left(0.64-1.1 M W / \mathbf{m}^{2}\right)$ show an increase by a factor 1.2-1.3 compared to the case $n^{\circ} 3$ and thus 1.6-2.4 compared to steady-state simulation $\left(\right.$ case n $\left.^{\circ} 2\right)$.
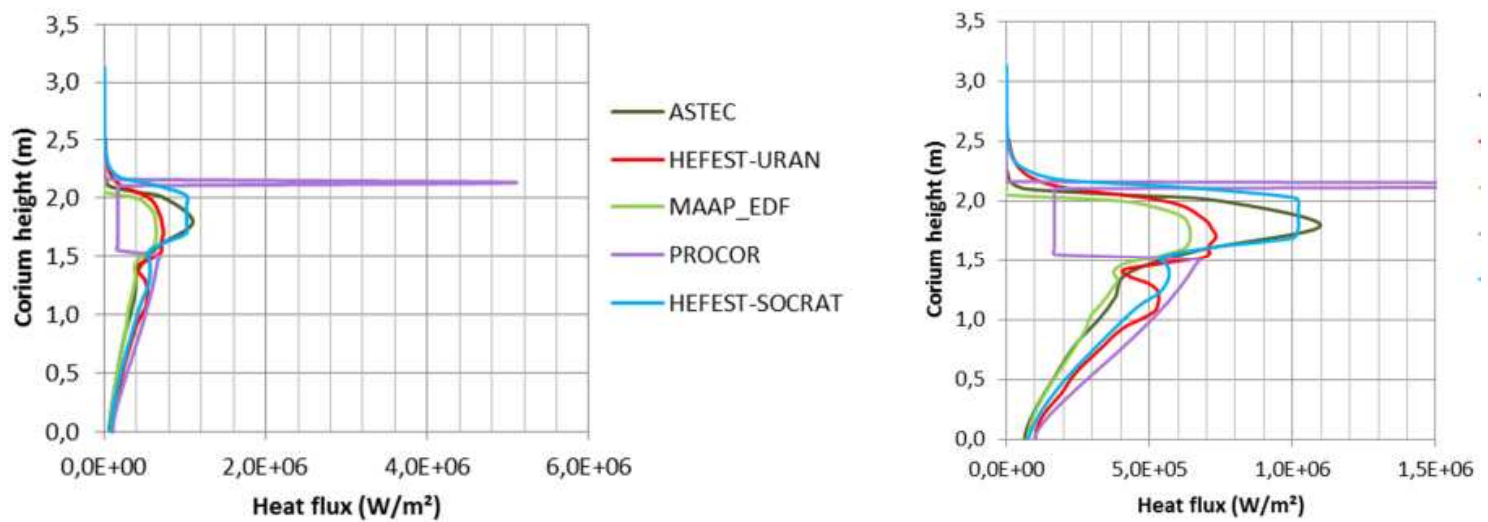

Figure 12 Profiles of heat flux along the outer vessel wall when maximum is reached (left) and zoom on low

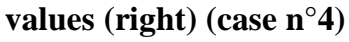

In Figure 13, the profiles of ablated vessel wall at steady state show a reduction of the minimum vessel thickness compared to the previous case $\left(n^{\circ} 3\right)$. This reduction due to the consideration of thermochemical effects is consistent for all codes and equal to about $\mathbf{1 c m}$, except for PROCOR code, in which the minimum thickness is reduced of $4 \mathrm{~cm}$. The composition of the metal layer is modified due to the thermochemical interaction as presented in Figure 14, with incorporation of about 8-8.5t of metallic Uranium and reduction of the mass of Zirconium (3-4t) compared to the previous case $n^{\circ} 3(7.5 \mathrm{t})$. This interaction with the oxide pool is very fast in ASTEC, HEFESTSOCRAT and HEFEST-URAN codes and takes about 5,000s in MAAP_EDF and PROCOR codes. It is also associated to a transfer of fission products in the metallic phase leading to have a fraction of the residual power (15$20 \%$ ) in the top metal layer as illustrated in Figure 13. Finally, it could be noticed that the thermochemical equilibrium model used in ASTEC, MAAP_EDF and PROCOR (from Salay and Fichot, 2005), allows miscibility of a small part of $\mathrm{UO}_{2}$ and $\mathrm{ZrO}_{2}$ in the metallic phase (2t).
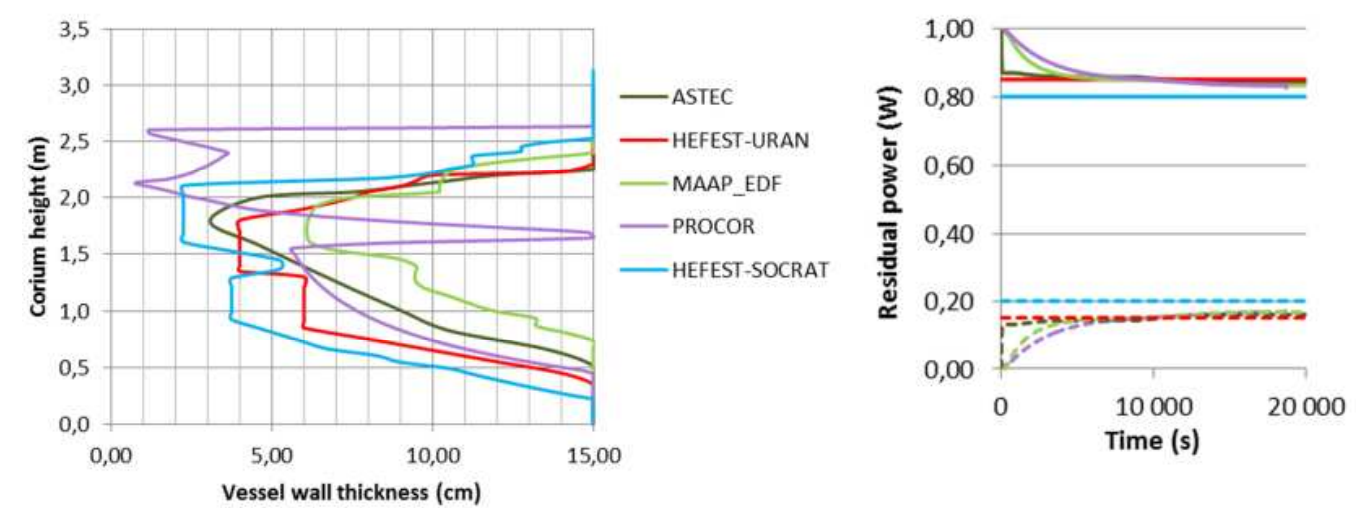

Figure 13 Ablated vessel wall at steady state (left) and residual power distribution between oxide (full lines) and metal (dashed lines) phases $^{9}$ (right) $\left(\right.$ case $\left.^{\circ}{ }^{4}\right)$

\footnotetext{
${ }^{9}$ It is constant and usually taken as $15 \%$ in the metal / $85 \%$ in the oxide in HEFEST-URAN code, in accordance with data from Ozrin et al. (2013)
} 

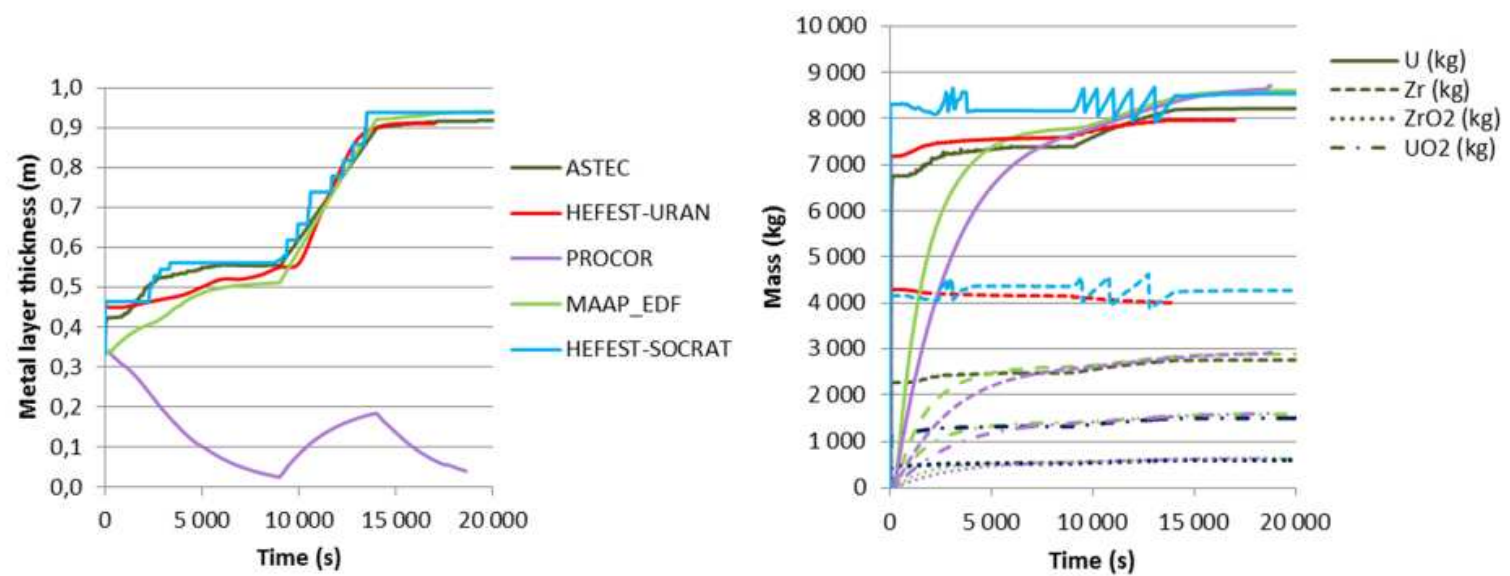

Figure 14 Evolution of the thickness (left) and of the composition ${ }^{10}$ (right) of the top metal layer in addition to

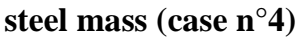

\section{Sensitivity analysis}

A sensitivity analysis based on the last transient configuration (case $n^{\circ} 4$ ), which is the most complete and involved all the relevant phenomena was also performed. The idea was to cover the variation of the main parameters identified as leading to the main differences in the steady-state configurations (cf. $§ 4.1$ ), in the range between lower and upper values implemented by default in the different codes used (cf. Table 3):

- $\quad$ Liquidus temperature of the metallic layer ([1600K-1778K], the solidus being defined 50K below);

- Dynamic viscosity of the metallic layer $\left[4.07 \times 10^{-3}-2.24 \times 10^{-2} \mathrm{~Pa} . \mathrm{s}\right]$;

- Thermal expansion coefficient of the metal layer $\left[2.9 \times 10^{-5}-1.17 \times 10^{-4} \mathrm{~K}^{-1}\right]$;

- Emissivity of the top metal layer [0.2-0.4].

A set of 200 calculations was defined for this sensitivity study and a uniform distribution law considered for the parameters over their range of variation. ASTEC, HEFEST-SOCRAT, MAAP ${ }^{11}$ and PROCOR codes participated in this study. In the case of PROCOR, the modelling of the crust being the main contributor to the minimum vessel thickness obtained, the sensitivity study was performed considering the calculation $n^{\circ} 3$ (without effects of thermochemistry).

The range of variation of the minimum thickness of the vessel wall obtained is presented in Figure 15 and is in accordance with the range of results obtained by the different codes. This analysis illustrates the non-negligible impact of the uncertainties associated to the metal layer properties. Without considering the thermochemical effects (PROCOR evaluations) the values for the minimum thickness are higher but the associated overestimation can be evaluated of about $1 \mathrm{~cm}$ as identified previously.

\footnotetext{
${ }^{10}$ For PROCOR, it is the composition of the metal layer after interaction below the oxide crust. The top layer remains only composed by steel.

${ }^{11}$ Coupled with OpentTUNS (Baudin et al. 2015)
} 


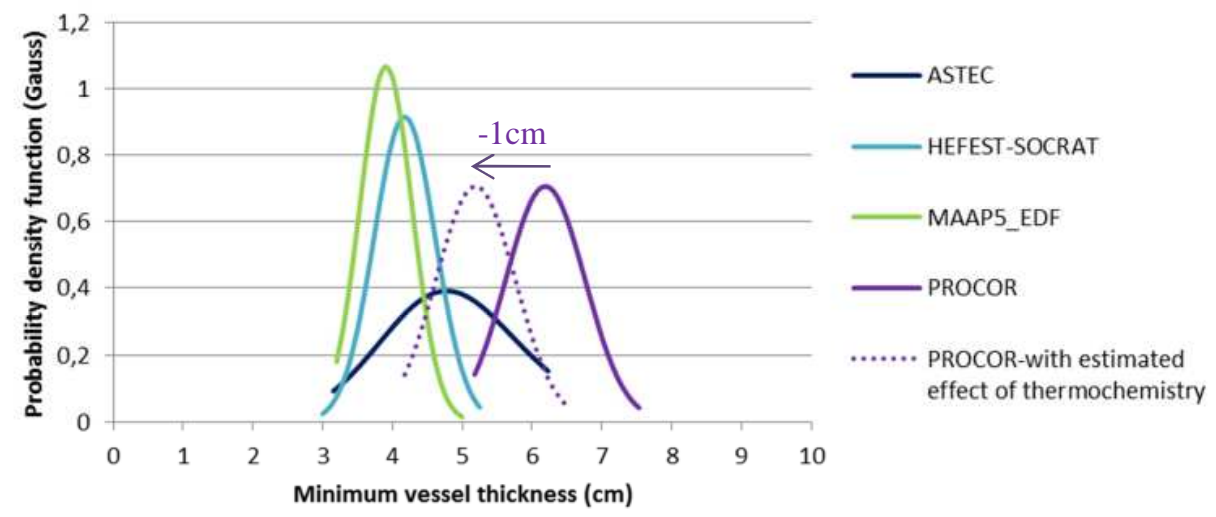

Figure 15 Probability density function obtained for the minimum vessel thickness in case $n^{\circ} 4$ for ASTEC, HEFEST-SOCRAT and MAAP codes and in case $n^{\circ} 3$ for PROCOR code

Results of the standard regression coefficients of Bravais-Pearson obtained for the 4 parameters considered show that the melting temperature of the metal layer and its emissivity are the main parameters, which impact significantly the power dissipated by radiation in this test configuration. Then, the viscosity of the metallic layer and its thermal expansion coefficient also play a role, as previously identified in Figure 7.

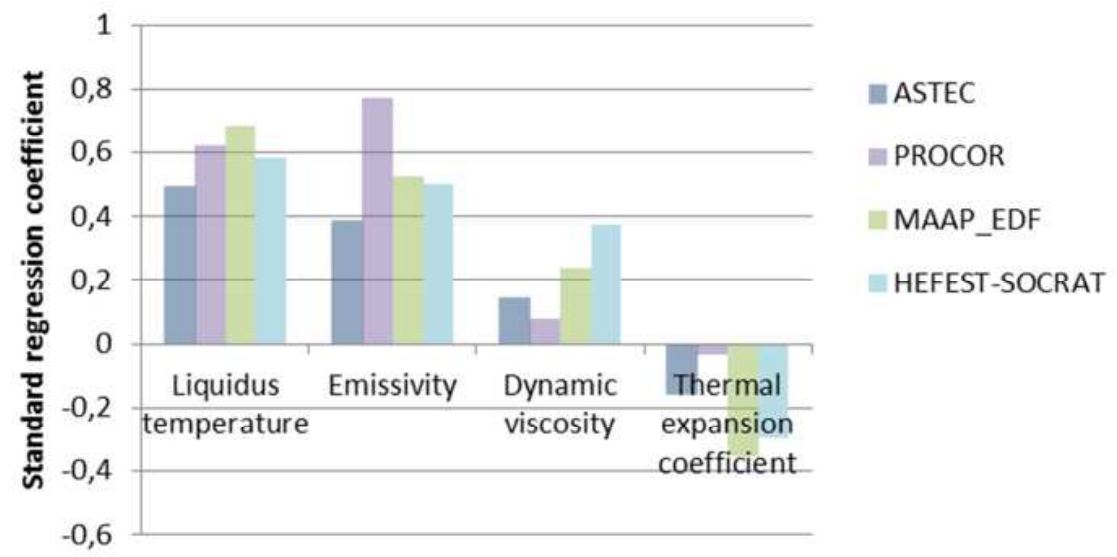

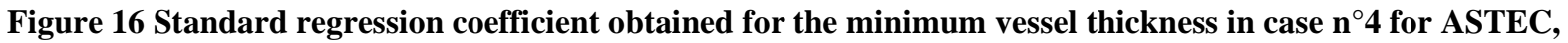
HEFEST-SOCRAT and MAAP codes and in case $n^{\circ} 3$ for PROCOR code

\section{Configuration involving inverse stratification}

Only the 4 following codes, ASTEC, HEFEST-URAN, MAAP5_EDF and PROCOR, took part to this last case since this configuration with stratification inversion requires advanced models to deal with this specific transient stratification evolution. The details of the initial corium configuration and of the imposed boundary conditions are summarized in Table 1 and illustrated in Figure 2. Two phases for molten steel incorporation in the pool are considered: the first one corresponding to the progressive melting of a plate submerged in the oxide pool and the second one being the relocation of molten steel on top of the pool as considered in previous transient configurations studied (cases $n^{\circ} 3$ and 4). Molten steel coming from the progressive ablation of the vessel wall is also calculated during the transient.

Results for the maximum heat flux profile reached at the outer surface of the vessel are presented in Figure 17. 


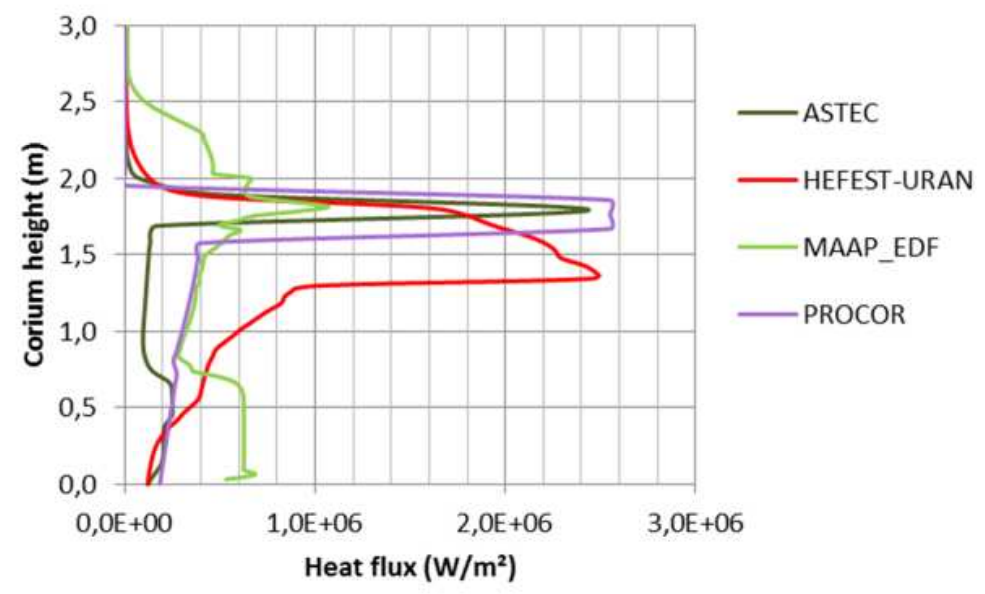

Figure 17 Profiles of heat flux along the outer vessel wall when maximum is reached (case $\mathbf{n}^{\circ} 5$ )

It is worth noting that in this case, for the sake of comparison, the oxide crust between the two metal layers is not considered anymore in PROCOR results. For each code, the maximum heat flux is multiplied by factor 2 or 3 compared to case without stratification inversion.

Looking at the metal phase evolution (cf. Figure 18), it is shown that the stratification inversion is observed in all simulations, with first the formation of a heavy metal layer and then the progressive decrease of its density up to its relocation to the top of the oxide pool (decrease of bottom metal layer mass and increase of the top one). However, a significant variability of stratification kinetics and threshold for inversion evaluated in the codes is observed. In ASTEC, MAAP_EDF and PROCOR codes, the maximum heat flux is obtained during 3-layers configurations when the top metal layer is thin (due to focusing effect). In HEFEST-URAN code, the maximum heat flux is obtained at stratification inversion due to the superheat of the metal after its relocation through the oxide pool.
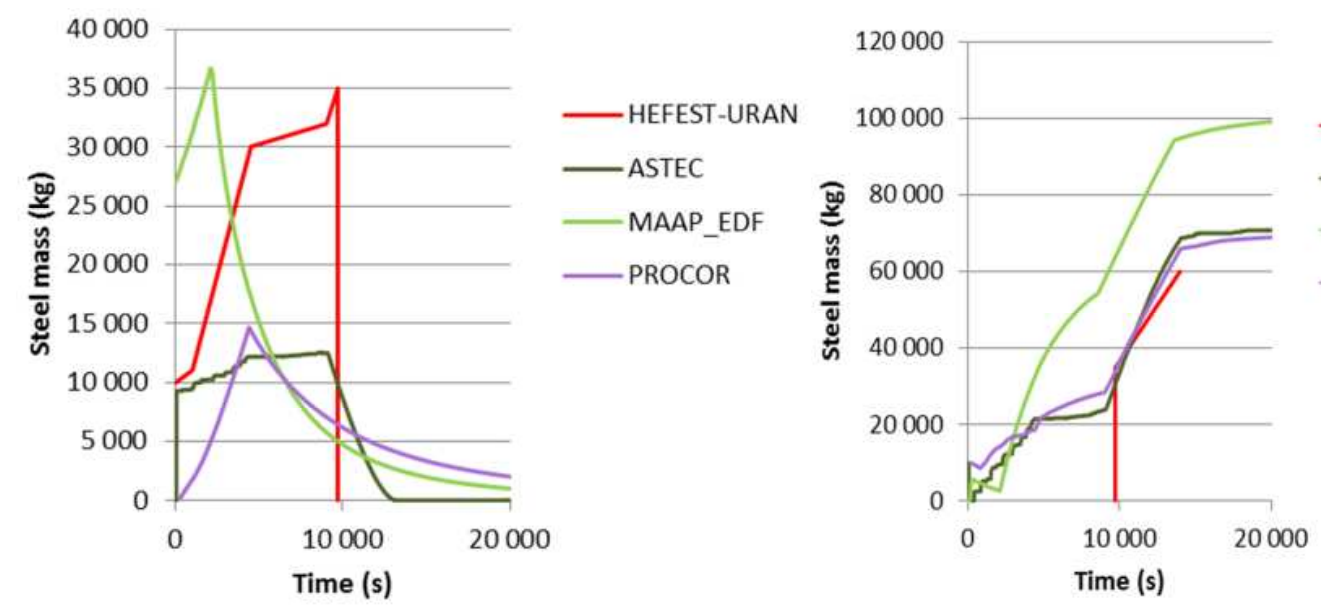

Figure 18 Steel mass evolution in the heavy metal layer (left) and in the top metal layer (right) (case $n^{\circ}$ )

Faster kinetics observed in MAAP_EDF code may be correlated to the lower maximum heat flux obtained (cf. Figure 17). However, it is important to keep in mind previous studies showing that lower maximum heat fluxes were already obtained for MAAP_EDF simulations as soon as radiative heat transfer are modelled at the top of the pool. This was mainly related to the material properties of the metal layer (cf. §4.1).

In Figure 19, the profiles of the ablated vessel wall are presented. The minimum vessel thickness is reached at the location of the top metal layer and is close to $1.5 \mathrm{~cm}$ for PROCOR, ASTEC and HEFEST-URAN evaluations and $3.5 \mathrm{~cm}$ for MAA_EDF code. In addition, a significant ablation at the bottom of the pool is observed for simulations in which the heavy metal mass is larger (HEFEST-URAN and MAAP_EDF codes). 


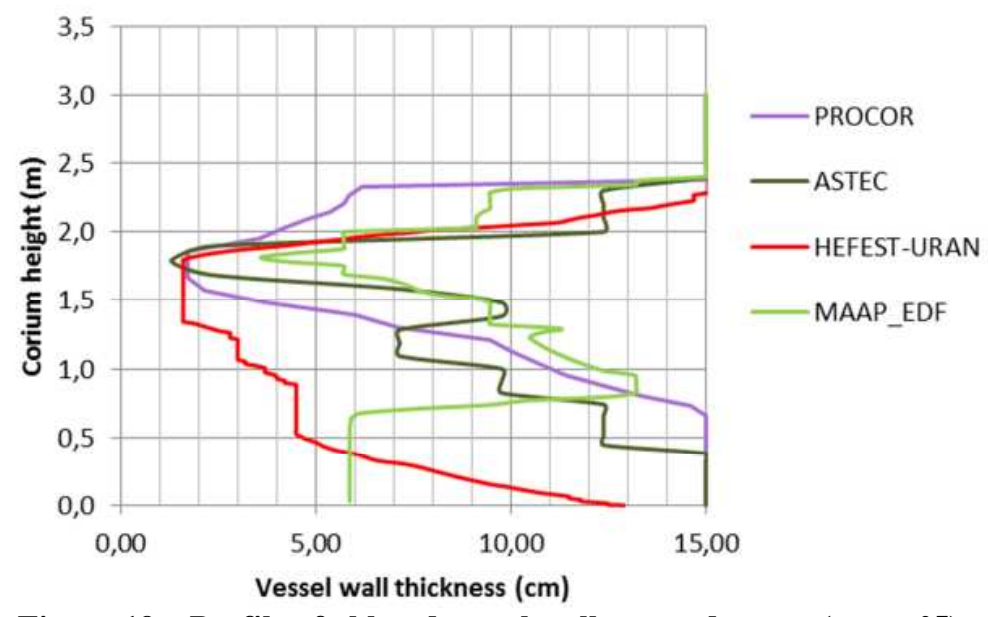

Figure 19 - Profile of ablated vessel wall at steady state (case $\mathbf{n}^{\circ} 5$ )

Although there is convergence among experts on the expected qualitative behavior for the corium stratification in this kind of complex configuration involving stratification inversion, it is still difficult to quantitatively evaluate the physical phenomena involved due to a lack of representative experimental data. Indeed, to study such configuration both material and scale effects play a major role and are obviously not easily achievable experimentally. Thus, the modelling of stratification inversion involves making assumptions in the codes. Among them, the most significant were identified as being:

- The kinetics of stratification inversion.

The evaluation of this kinetics includes the knowledge of the process of species transfers through the oxide crust and through the oxide pool, as well as the mixing resulting from Rayleigh-Taylor instability and the metal phase transport through the oxide pool.

- The heat transfers with the oxide pool during the relocation of the metal phase. This issue is important to better evaluate the risk associated to the metal superheat but is also highly dependent on the evaluation of the kinetics of stratification inversion mentioned above.

- The stability of the oxide crust in contact with molten steel. This oxide crust may be assumed to be present around the metal layer (due to the chemical equilibrium with the oxide) or not (non-equilibrium situations). The presence of the crust significantly changes the value of the heat fluxes, as illustrated by PROCOR results in case $n^{\circ} 4$.

In addition, the uncertainty associated to the heat flux evaluation in the thin top metal layer may also have a significant impact on the minimum vessel thickness evaluation. Indeed, heat transfer correlations commonly used for the top metal layer are not valid for layer with an aspect ratio (thickness/radius) below 0.1 (Bonnet and Seiler, 1999).

Thanks to different modelling choices and users' options implemented in the codes, the range of variability of the results depending on some physical uncertainties can be quantified. With ASTEC code, a sensitivity study was made to model parameters impacting:

- The kinetics for reaching the thermochemical equilibrium between oxide and metal layers: The reference case with $10^{-8} \mathrm{~m}^{2} / \mathrm{s}$ for the molecular diffusion coefficient of species is multiplied by 10 (faster kinetics) or divided by 10 (slower kinetics).

- The superheat of the metal layer after its relocation through the oxide pool: either it is assumed to be zero or it is assumed to be maximum (i.e. the metal being at the temperature of the oxide).

- The threshold for density inversion: either when the metal density becomes equal to the oxide density or when there is $2 \%$ of density difference with the oxide.

The results for the ablated vessel profiles are summarized in Figure 20. 


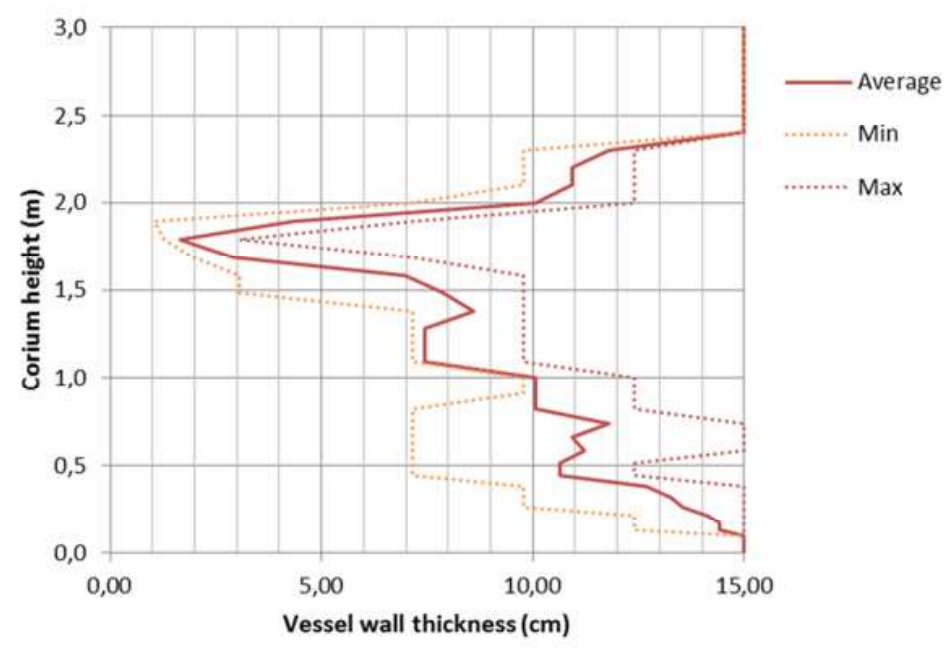

Figure 20 - Variability of ablated vessel wall profile obtained at steady state with ASTEC code (case $n^{\circ}$ )

It is shown that the variation of the minimum vessel thickness is evaluated about $2 \mathrm{~cm}( \pm 1 \mathrm{~cm})$. This variation remains limited despite the large range of variation considered for the uncertain physical processes. It can be explained by the impact of couple effects but also by the dominant impact of the kinetics of molten steel incorporation in the pool which is imposed in these simulations. Besides, a large variation of the wall ablation at the bottom is observed and confirms the scope of the results presented in Figure 19, with a significant impact of the heavy metal layer superheat and lifetime.

With MAAP_EDF code, a sensitivity study to model parameters was also performed and showed a range of variation for the minimum vessel thickness equal to $1 \mathrm{~cm}-6 \mathrm{~cm}$. It was shown that the uncertainties on the heat transfers in very thin top metal layer (below $3 \mathrm{~cm}$ ) lead to the worst case $(1 \mathrm{~cm}$ remaining vessel wall) with a maximum heat flux at the outer surface of the vessel wall of $2.8 \mathrm{MW} / \mathrm{m}^{2}$. Looking at the kinetics of stratification inversion, it was observed that very slow kinetics may prevent stratification inversion before incorporation of all the molten steel in the pool and then lead to a reduced maximum heat flux $0.7 \mathrm{MW} / \mathrm{m}^{2}$.

Obviously, in case of such complex transient evolutions (formation of heavy metal followed by inversion of stratification), the assumptions made in the physical models play an important role. They should be verified by comparison with experimental observations, even if relevant experimental data are still limited (mainly MASCA and CORDEB programs). At least, a consensus on modelling should be looked for, in order to reduce the sources of discrepancies.

\section{Conclusion}

A benchmark exercise on IVR was performed between 6 different codes in order to compare the best estimate results of each code and get a deeper understanding of the differences between implemented models. The exercise was made by the code developers themselves to limit somehow the potential user-effect. This crosswalk study followed a step by step approach with a gradual increase of complexity. It must be noted that a detailed comparison for lower head vessel modelling was already performed between MAAP_EDF and PROCOR codes (Bakouta et al., 2015) but it is the first exercise of this kind involving 6 different codes, either integral or dedicated to the lower head.

It was first checked that, when considering steady state configurations, the variability of the results for the evaluation of the maximum heat flux along the outer surface of vessel wall remains limited $( \pm 20 \%)$. It was highlighted that this dispersion is mainly due to the uncertainties in the metal layer dynamic viscosity, thermal expansion coefficient, emissivity and melting temperature. Dispersion in the values of physical properties cannot be avoided due to experimental uncertainties and numerous references in the literature. In addition, there are additional uncertainties induced by the mixing laws because the layers are actually mixtures. Nevertheless, recommendations should be made for the choice of reference values for the material properties of the metal and for their ranges of 
variability. In particular, for metal emissivity, a recommended value could be around 0.4 and values as low as 0.2 appear to be non-realistic and should be avoided. Also, for the melting temperature, the existence of eutectic mixtures in the $\mathrm{Fe}-\mathrm{U}-\mathrm{Zr}$ diagram should be considered.

Then, the importance of performing transient evaluation of IVR was illustrated by taking into account the progressive addition of steel in the corium due to melting of the vessel and of the upper structures. Because of the presence, at the beginning of the transient, of a thinner metal layer, the results of all codes indicate a possible increase of the maximum heat flux evaluated at the outer surface of the vessel. In such transient simulations, a large variability of the results for the minimum vessel thickness was evaluated (about $\pm 80 \%$ ), with a variation from less than $1 \mathrm{~cm}$ to $6 \mathrm{~cm}$. The differences between models leading to the most significant discrepancies in minimum vessel thickness evaluation have been identified, and the modelling of the oxide crust separating the oxide and the metal appears to play a major role. Depending on modelling assumption, this crust is assumed to be present around the metal layer after its interaction with this oxide (due to the global chemical equilibrium with the oxide) or not (local non-equilibrium). The chemical stability of the oxide crust in contact with molten steel and its impact on the kinetics of stratification were recently studied in the CORDEB experiments (Almjashev et al., 2018). It clearly indicates that the crust is stable for only a limited period of time and that the oxide/metal system may evolve out of equilibrium for some time. CORDEB results have also provided an order of magnitude of the kinetics of mass transfer through the thin crust between oxide and top metal layers. However, further studies are needed to validate the modelling implemented in the codes.

Looking at a simpler situation where the thermochemical interactions between the corium pool and the molten steel are neglected, this dispersion in minimum vessel thickness evaluation is reduced to $\pm 40 \%$ corresponding to $5 \mathrm{~cm} \pm 2 \mathrm{~cm}$. A dedicated sensitivity analysis has shown that the main contributors to that dispersion are the uncertainties on physical properties of the metal layer. The impact of other parameters and specificities of models implementation in the codes appears to be less significant in this configuration.

Finally, the specific scenario with formation of a heavy metal layer followed by the transient stratification inversion was considered. This more complex situation is expected to occur in fast kinetics SA scenarios when the initial mass of molten steel incorporated in the pool remains limited. However, it is particularly interesting because it is the most challenging situation for the IVR strategy. Regarding the physical phenomena involved and the code modelling, this last configuration is also more complex and associated uncertainties are larger. In particular, the issues associated to the evaluation of the kinetics of stratification inversion and to the evaluation of the heat fluxes in the thin metal layer were highlighted. Despite those difficulties, it was shown that variation of minimum vessel thickness remains limited $\pm 40 \%(2.5 \mathrm{~cm} \pm 1 \mathrm{~m})$ between codes and up to $\pm 70 \%(3.5 \mathrm{~cm} \pm 2.5 \mathrm{~cm})$ when variability due to model uncertainties are considered. In addition, a common output of all simulations was that this minimum thickness is always reached during stratification inversion process. The maximum (transient) heat flux is multiplied by a factor 2-3 compared to configuration with a single metal layer on top.

In the current context of construction of Gen III plants throughout the world, many of them with IVR strategy, there is a need for a reliable assessment of the codes used for safety evaluation. This benchmark clearly shows that transient evolutions lead to higher heat fluxes and thinner vessel wall than the values evaluated with a hypothetical (and most of the time unrealistic) "steady state". Therefore codes used for safety evaluation of IVR should be able to describe transient stratification process and chemical interactions between oxide and metal. The set of situations considered in this benchmark and the results presented might be used as a reference for other codes, to demonstrate their ability to simulate IVR in steady state and transient situations, taking into account the latest knowledge on thermochemistry, oxide/metal stratification and possible configurations with stratification inversion.

\section{Acknowledgments}

The authors wish to acknowledge funding and support provided by the European Project H2020 IVMR No. 662157.

\section{References}

Almjashev V.I., Granovsky V.S., Khabensky V.B., Kotova S.Yu., Krushinov E.V., Sulatsky A.A., Vitol S.A., Gusarov V.V., Fichot F., Michel B., Piluso P., Le Tellier R., Fischer M., Le Guennic C., Bakouta N., Experimental study of transient phenomena in the three-liquid oxidic-metallic corium pool, Nuclear Engineering and Design, 332, pp. 31-37, 2018 
Asfia S.J., Dhir V.K., An experimental study of natural convection in a volumetrically heated spherical pool bounded on top with a rigid wall, Nuclear Engineering and Design 163, p 333-348, 1996

Bakouta N., Le Tellier R. \& Saas L., Assessment of advanced corium-in-lower-head models in MAAP and PROCOR codes, proceedings of the $7^{\text {th }}$ European Review Meeting on Severe Accident Research ERMSAR, 2015.

Bonnet J.M., Seiler J.M., Thermal hydraulic phenomena in corium pool: the BALI experiment, proceedings of ICONE7 Conference, Tokyo (Japan), 1999.

Bakouta N., Torkhani M., Le Belguet A., In-vessel corium modelling in the MAAP_EDF code, proceedings of the $8^{\text {th }}$ ERMSAR Conference (European Review Meeting on Severe Accident Research) Warsaw, Poland, 15-18 May 2017.

Baudin M., Dutfoy A., Iooss B., Popelin AL. OpenTURNS: An Industrial Software for Uncertainty Quantification in Simulation. In: Ghanem R., Higdon D., Owhadi H. (eds) Handbook of Uncertainty Quantification. Springer, Cham, 2015. https://rd.springer.com/referenceworkentry/10.1007/978-3-319-11259-6_64-1.

Carénini L., Fichot F., The Impact of Transient Behavior of Corium in the Lower Head of a Reactor Vessel for InVessel Melt Retention Strategies, proceedings of ICONE24 Conference, Charlotte (USA), 2016.

Chawla T.C. and Chan S.H., Heat transfer from vertical/inclined boundaries of heat generating boiling pools, Journal of Heat Transfer, Vol.104, pp. 465-473 (1982)

Churchill S. W., Chu H. H., Correlating equations for laminar and turbulent free convection from a vertical plate, Int. J. Heat Mass Transfer, Vol. 18, pp. 1323-1329, 1975.

Duspiva J., Progress in Simulation of IVR Strategy for VVER-1000/320 Reactor with MELCOR code, proceedings of $17^{\text {th }}$ NURETH Conference, Xi' an (China), September 3-8, 2017.

Esmaili H., Khatib-Rhabar M., "Analysis of in-vessel retention and ex-vessel fuel coolant interaction for AP-1000", NUREG/CR-6849, ERI/NRC 04-201, 2004.

Fichot F., Carénini L., Sangiorgi M., Hermsmeyer S., Miassoedov A., Bechta S., Zdarek J., Guenadou D., Some considerations to improve the methodology to assess In-Vessel Retention strategy for high-power reactors, Annals of Nuclear Energy, Vol. 119, pp. 26-45, 2018.

Fichot F., Carénini L., N. Bakouta, H. Esmaili, L. Humphries, T. Laato, R. Le Tellier, L. Saas, I. Melnikov, P. Pandazis, S. Weber, R.J. Park, A. Filippov, V. Strizhov, "Elaboration of a PIRT for the modelling of In-Vessel Retention", proceedings of $9^{\text {th }}$ ERMSAR2019 Conference, Prague (Czech Republic), March 18-20, 2019.

Filippov A.S., Drobyshevsky N.I., Kisselev A.E., Strizhov V.F., Fokin A.L. SOCRAT/HEFEST code: models of VVER core melt interaction with reactor structures under severe accident conditions // Bull. Russ. Acad. Sci., Energetics, 3, P.4-24, 2010 (in Russian).

Filippov A.S., Drobyshevsky N.I., Kamenskay D.D., Kisselev A.E., Moiseenko E.V. End-to-end technology of modeling a melt-structure interaction during IVMR in VVER with HEFEST-URAN toolkit. Proceedings of $22^{\text {nd }}$ Int. Conf. Nuclear Engineering, ICONE22, Prague (Czech Republic), July 7-11, 2014.

Gencheva R., Stefanova A., Groudev P., Chatterjee B., Mukhopadhyay D., Study of in-vessel melt retention for VVER-1000/v320 reactor, Nuclear Engineering and Design, 298, pp. 208-217, 2016.

Henry R.E., Fauske H.K., "External cooling of a reactor vessel under severe accident conditions", Nuclear Engineering and Design, Vol.139, pp. 31-43, 1993.

Jahn M., Reinke H.H., "Free convection heat transfer with internal energies sources: calculation and measurements", proceedings of the $5^{\text {th }}$ Int. Heat Transfer Conference, Tokyo (Japan), 1974.

Kelkar K.M., Khankari K.K., Patankar S.V., Computational modelling of turbulent natural convection in flows simulating reactor core melt, Final Rep, Sandia National Laboratories, Albuquerque, NM, December 1993

Knudson D.L., Rempe, J.L., Condie K.G., Suh K.Y., Cheung F.-B., Kim S.-B., " Late-phase melt conditions affecting the potential for in-vessel retention in high power reactors", Nuclear Engineering and Design, Vol. 230, 2004.

Kymälainen O., Tuomisto H. and Theofanous T.G., In-vessel retention of corium at the Loviisa plant, Nuclear Engineering and Design, 169, 1997.

Le Tellier R., Saas L., Bajard S., Transient stratification modelling of a corium pool in a LWR vessel lower head, Nuclear Engineering and Design 287, pp. 68-77, 2015. 
Ozrin V.D., Tarasov V.I., Filippov A.S., Moiseenko E.V., Tarasov O.V.. Distribution of fission product residual decay heat in stratified core melt of LWR and its influence on sidewall heat flux. // Nucl. Eng. Des. 107-115, Vol. 261, 2013.

Pandazis P., Weber S., Investigation of a severe accident late phase scenario in a PWR with ATHLET-CD, proceedings of the $27^{\text {th }}$ Nuclear Energy for New Europe Conference, Portoroz (Slovenia), 2018.

Rempe J.L., Knudson D. L., Allison C. M., Thinnes G.L., Atwood C.L., Cebull M.J., Potential for AP600 In-Vessel Retention through Ex-Vessel Flooding, INEEL/EXT-97-00779, December 1997.

Rempe J.L., Knudson D.L., Condie K.G., Suh K.Y., Cheung F.-B., Kim S.-B., Corium retention for high power reactors by an in-vessel core catcher in combination with External Reactor Vessel Cooling, Nuclear Engineering and Design, Vol. 230, 2004.

Salay M. and Fichot F., Modeling of metal-oxide corium stratification in the lower plenum of a reactor vessel, Proceedings of NURETH-11 Conference, Avignon (France), 2005.

Theofanous T.G., Liu C., Addition S., Angelini S., Kymälainen O. and Salmassi T., In-vessel coolability and retention of core melt, Nuclear Engineering and Design, Vol. 169, 1997.

Tsurikov D., MASCA2 Project: Major Activities and Results, Proceedings of MASCA2 Seminar, Cadarache (France), October 11-12, 2007.

Tuomisto H., Theofanous T.G., A consistent approach to severe accident management, Nuclear Engineering and Design, Vol. 148, 1994.

Tuomisto H., Sehgal B. R., MASCA results and the case for in vessel melt retention, Proceedings of MASCA2 Seminar, Cadarache (France), October 11-12, 2007.

Whang S., Park H.S., Moriyama K., Lim K., Cho Y.J., Kim M.H., Uncertainty analysis of in-vessel retention in a high power reactor during severe accident, Nuclear Engineering and Design, Vol. 319, 2017.

Xing J., Song D., Wu Y., HPR1000: Advanced Pressurized Water Reactor with Active and Passive Safety, Engineering, Vol. 2, pp. 79-87, 2016.

Zdarek J., Krhounek L., Batek D., Zvonarev Yu., Volchek A., Kobzar V., Budaev M., Assessment of In-Vessel Melt Retention possibility for VVER-1000/320, proceedings of $6^{\text {th }}$ European Review Meeting on Severe Accident Research (ERMSAR-2013), Avignon (France), October 2-4, 2013. 


\section{Appendix - Analytical evaluation of steady state configurations (cases $n^{\circ} 1$ and 2)}

\section{Nomenclature}

\section{Latin letters}

$C_{p} \quad$ Heat capacity $[\mathrm{J} / \mathrm{K} / \mathrm{kg}]$

D Diffusion coefficient $\left[\mathrm{m}^{2} / \mathrm{s}\right]$

g Standard gravity $\left[\mathrm{m} / \mathrm{s}^{2}\right]$

$\mathrm{H} \quad$ Layer height [m]

k Thermal conductivity $[\mathrm{W} / \mathrm{m} / \mathrm{K}]$

$P_{\text {res }} \quad$ Residual power [W]

$\dot{Q} \quad$ Volumetric power $\left[\mathrm{W} / \mathrm{m}^{3}\right]$

$\mathrm{R} \quad$ Vessel radius [m]

S Surface $\left[\mathrm{m}^{2}\right]$

$\mathrm{T}_{\text {liq }} \quad$ Liquidus temperature [K]

$\mathrm{T}_{\text {pool }} \quad$ Bulk temperature of the layer [K]

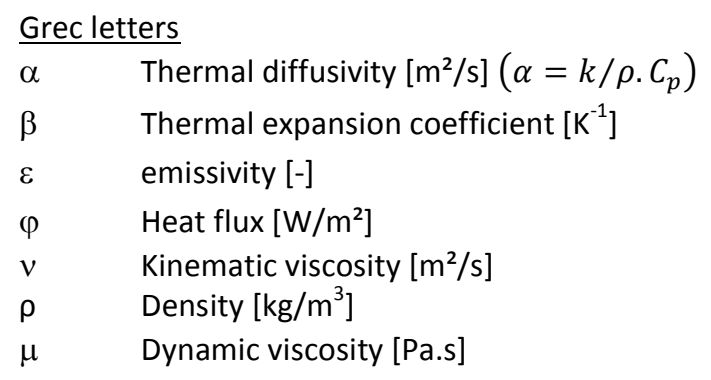

Steady-state configurations $n^{\circ} 1$ and 2 defined for the benchmark exercise (cf. Figure 1) may be evaluated in an analytical way. The order of magnitude of the heat fluxes and the layers temperatures are estimated in the following parts. The values of the physical properties used for this simple evaluation are the ones presented in the table below.

Table 4 - Material properties corresponding to the benchmarking case (from Esmali and Khatib-Rahbar, 2004)

\begin{tabular}{|c|c|c|}
\hline & Parameter & Value \\
\hline \multirow{6}{*}{ 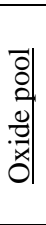 } & Density & $8191 \mathrm{~kg} / \mathrm{m}^{3}$ \\
\hline & Thermal conductivity & $5.3 \mathrm{~W} / \mathrm{m} / \mathrm{K}$ \\
\hline & Dynamic viscosity & $4.67 \times 10^{-3} \mathrm{~Pa} . \mathrm{s}$ \\
\hline & Specific heat capacity & $533 \mathrm{~J} / \mathrm{kg} / \mathrm{K}$ \\
\hline & Thermal expansion coefficient & $1.05 \times 10^{-4} \mathrm{~K}^{-1}$ \\
\hline & Melting temperature & $2950 \mathrm{~K}$ \\
\hline \multirow{6}{*}{ 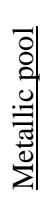 } & Density & $6899 \mathrm{~kg} / \mathrm{m}^{3}$ \\
\hline & Thermal conductivity & $25 \mathrm{~W} / \mathrm{m} / \mathrm{K}$ \\
\hline & Dynamic viscosity & $4.07 \times 10^{-3} \mathrm{~Pa} . \mathrm{s}$ \\
\hline & Specific heat capacity & $789.5 \mathrm{~J} / \mathrm{kg} / \mathrm{K}$ \\
\hline & Thermal expansion coefficient & $1.11 \times 10^{-4} \mathrm{~K}^{-1}$ \\
\hline & Melting temperature & $1600 \mathrm{~K}$ \\
\hline
\end{tabular}

\section{Determination of the temperature of the oxide pool}

It is assumed here that all the residual power is produced in the oxide pool. The governing parameter is the internal Rayleigh number:

$$
R a_{o x}=\frac{g \beta_{o x} \dot{Q}_{o x} H^{5}}{\alpha_{o x} k_{o x} v_{o x}}
$$

In the present case, the oxide pool has a height $H \sim 1.5 \mathrm{~m}$. The residual power in the oxide pool of $P_{\text {res }}=14 M W$ corresponds to a volumetric power of $\dot{Q}_{o x} \sim 1.3 \mathrm{MW} / \mathrm{m}^{3}$. This gives $R a_{o x} \sim 3.10^{15}$.

There is a partition of that power and one part is transferred to the vessel wall $\left(\varphi_{d n} S_{d n}\right)$ and the complementary part is transferred to the top metal layer $\left(\varphi_{u p} S_{u p}\right)$.

$$
\varphi_{d n} S_{d n}+\varphi_{u p} S_{u p}=P_{r e s}
$$

Heat fluxes are evaluated thanks to experimental correlations, assuming that the oxide pool is surrounded by a crust which imposes a uniform boundary condition at the liquidus temperature of the oxide mixture: $T_{\text {liq }}^{o x}$. With this assumption, both heat fluxes are expressed as a function of the temperature difference $\left(T_{\text {pool }}^{o x}-T_{\text {liq }}^{o x}\right)$.

$$
\varphi_{d n}=\frac{k_{o x}}{H} N u_{d n}\left(T_{\text {pool }}^{o x}-T_{\text {liq }}^{o x}\right) ; \varphi_{u p}=\frac{k_{o x}}{H} N u_{u p}\left(T_{\text {pool }}^{o x}-T_{\text {liq }}^{o x}\right)
$$


From that, we directly get the temperature of the oxide pool:

$$
T_{\text {pool }}^{o x}=T_{\text {liq }}^{o x}+P_{\text {res }} \frac{H}{k_{\text {ox }}}\left(N u_{d n} S_{d n}+N u_{u p} S_{u p}\right)^{-1}
$$

If we choose COPO/BALI correlations (Bonnet and Seiler, 1999), we get:

$$
N u_{d n}=0.131 R a_{o x}{ }^{0.25}\left(\frac{H}{R}\right)^{0.19} ; N u_{u p}=0.381 R a_{o x} 0.234
$$

And $T_{\text {pool }}^{o x}=T_{\text {liq }}^{o x}+110$, where the liquidus temperature of the oxide may vary according to the code or the user's choice and is considered in this benchmark at $T_{\text {liq }}^{o x} \sim 2950 \mathrm{~K}$.

\section{Determination of the partition of power in the oxide between top and bottom}

One important point is that, with the assumptions chosen, the partition of residual power between bottom and top is independent of the boundary conditions and depends only on the internal Rayleigh number and on the shape of the vessel:

$$
\frac{\varphi_{u p}}{\varphi_{d n}}=\frac{N u_{u p}}{N u_{d n}}=\frac{0.131}{0.381} R a_{o x}{ }^{(0.234-0.25)} \text { and } \frac{\varphi_{u p} S_{u p}}{\varphi_{d n} S_{d n}+\varphi_{u p} S_{u p}}=\frac{N u_{u p} S_{u p}}{N u_{d n} S_{d n}+N u_{u p} S_{u p}} \sim 0.52
$$

Therefore, we see that close to $50 \%$ of the residual power is transferred to the top metal layer, independently of the boundary conditions. With the surfaces considered in this benchmark, the bottom and top heat fluxes are:

$$
\varphi_{d n}=0.36 \mathrm{MW} / \mathrm{m}^{2} ; \varphi_{u p}=0.62 \mathrm{MW} / \mathrm{m}^{2}
$$

\section{Determination of the maximum heat flux in the oxide}

Correlations derived from experimental data provide the heat flux profile along the vessel wall: $\frac{N u(\theta)}{N u_{d n}}=f(\theta)$.

The maximum value is found at the top. Using the distribution function proposed in Theofanous et al. (1996) for a hemispherical vessel leads to a "peaking factor" of 1.8 and, therefore:

$$
\varphi_{d n}^{\max }=0.64 M W / m^{2}
$$

\section{Determination of the heat flux along the top metal layer}

For the metal layer, natural convection is driven by the contact with the hot oxide pool and the cooling along the side wall and also, possibly, at the top of the metal layer (radiative heat transfer). The standard Rayleigh number is used:

$$
R a_{m e t}=\frac{g \beta_{m e t}\left(T_{\text {pool }}^{\text {met }}-T_{\text {liq }}^{\text {wall }}\right) H_{m e t}{ }^{3}}{\alpha_{m e t} v_{m e t}}
$$

The expression of the heat flux along the side wall is:

$$
\varphi_{\text {met }}=\frac{k_{\text {met }}}{H_{\text {met }}} N u_{\text {met }}\left(T_{\text {pool }}^{\text {met }}-T_{\text {liq }}^{\text {wall }}\right)
$$

Where, using the Chawla-Chan correlation in turbulent regime (Chawla and Chan, 1982), we have:

$$
\varphi_{\text {met }}=0.076 k_{\text {met }}\left(\frac{g \beta_{\text {met }}}{\alpha_{\text {met }} v_{\text {met }}}\right)^{1 / 3}\left(T_{\text {pool }}^{\text {met }}-T_{\text {liq }}^{\text {wall }}\right)^{4 / 3}
$$

If, we assume that there is no heat loss from the top (conservative assumption neglecting radiative heat transfer with upper structures), the conservation of energy gives: $\varphi_{u p} S_{u p}=\varphi_{\text {met }} S_{\text {met }}$

We recall that, because of the partition of energy found previously, this is equivalent, in the present case, to the relation: $\varphi_{\text {met }} S_{\text {met }}=0.52 P_{\text {res }}$

Therefore we obtain, for the heat flux along the metal layer (for a height of metal layer estimated to $90 \mathrm{~cm}$ ):

$$
\varphi_{\text {met }}=0.64 \mathrm{MW} / \mathrm{m}^{2}
$$

If we assume a radiative heat flux with the upper structures: $\varphi_{\text {met }} S_{\text {met }}+\varphi_{\text {radi }} S_{\text {up }}=0.52 P_{\text {res }}$ With $\varphi_{\text {radi }}=\varepsilon \sigma\left(T_{u p}{ }^{4}-T_{\text {structures }}{ }^{4}\right)$ 
Using the Globe-Dropkin correlation (Globe and Dropkin, 1959) for the upwards heat transfers, allows evaluating the heat flux repartition, considering $T_{\text {structures }}=950 \mathrm{~K}$ and $\varepsilon=0.38$ :

$$
\varphi_{\text {met }}=0.5 \mathrm{MW} / \mathrm{m}^{2} ; \varphi_{\text {radi }}=0.15 \mathrm{MW} / \mathrm{m}^{2}
$$

\section{Determination of the temperature of the metal pool}

The temperature of the metal pool, in the case $\varphi_{\text {met }}=0.5 \mathrm{MW} / \mathrm{m}^{2}$, is obtained by:

$$
T_{\text {pool }}^{\text {met }}=T_{\text {liq }}^{\text {wall }}+\left(\frac{\varphi_{\text {met }}}{0.076 k_{\text {met }}}\right)^{3 / 4}\left(\frac{\alpha_{\text {met }} v_{m e t}}{g \beta_{\text {met }}}\right)^{1 / 4} \sim T_{\text {liq }}^{\text {wall }}+82
$$

where the melting temperature of the wall is evaluated in this benchmark at $T_{\text {liq }}^{\text {wall }} \sim 1600 \mathrm{~K}$.

\section{References}

Bonnet J.M., Seiler J.M., "Thermal hydraulic phenomena in corium pool: the BALI experiment", proceedings of ICONE7 Conference, Tokyo (Japan) (1999)

Chawla T.C. and Chan S.H., "Heat transfer from vertical/inclined boundaries of heat generating boiling pools", Journal of Heat Transfer, Vol.104, pp. 465-473 (1982)

Globe S. and Dropkin D., "Natural convection heat transfer liquids confined by two horizontal plates and heated from below", Journal of Heat Transfer, Vol.81, pp. 24-28 (1959)

Theofanous T.G., Liu C., Additon S., Angelini S., Kymäläinen O., Salmassi T., "In-Vessel Coolability and Retention of a Core Melt”. DOE/ID-10460, October 1996 